\title{
əOn the Consequences of PBL Scheme Diffusion on UTLS Wave and Turbulence Representation in High-Resolution NWP Models
}

\author{
Domingo Muñoz-Esparza, Robert D. Sharman, and Stanley B. Trier \\ National Center for Atmospheric Research, Boulder, Colorado
}

(Manuscript received 31 March 2020, in final form 6 July 2020)

\begin{abstract}
Mesoscale numerical weather prediction (NWP) models are routinely exercised at kilometer-scale horizontal grid spacings $(\Delta x)$. Such fine grids will usually allow at least partial resolution of small-scale gravity waves and turbulence in the upper troposphere and lower stratosphere (UTLS). However, planetary boundary layer (PBL) parameterization schemes used with these NWP model simulations typically apply explicit subgrid-scale vertical diffusion throughout the entire vertical extent of the domain, an effect that cannot be ignored. By way of an example case of observed widespread turbulence over the U.S. Great Plains, we demonstrate that the PBL scheme's mixing in NWP model simulations of $\Delta x=1 \mathrm{~km}$ can have significant effects on the onset and characteristics of the modeled UTLS gravity waves. Qualitatively, PBL scheme diffusion is found to affect not only background conditions responsible for UTLS wave activity, but also to control the local vertical mixing that triggers or hinders the onset and propagation of these waves. Comparisons are made to a reference large-eddy simulation with $\Delta x=250 \mathrm{~m}$ to statistically quantify these effects. A significant and systematic overestimation of resolved vertical velocities, wave-scale fluxes, and kinetic energy is uncovered in the $1-\mathrm{km}$ simulations, both in clear-air and in-cloud conditions. These findings are especially relevant for upper-level gravity wave and turbulence simulations using high-resolution kilometer-scale NWP models.
\end{abstract}

KEYWORDS: Atmosphere; Convective-scale processes; Turbulence; Numerical weather prediction/forecasting; Mesoscale models; Subgrid-scale processes

\section{Introduction}

Unexpected turbulence events are a common threat to commercial and general aviation. Turbulence encounters can result in serious injuries to aircraft occupants and in the rerouting of flights, which can significantly disrupt operations, resulting in a reduction of the National Airspace System (NAS) capacity. In general, these turbulence events are difficult to predict given their intricate connection with complex weather scenarios, and the disparate-scale interactions between large-scale circulation patterns and smaller-scale waves and instabilities that generate turbulence. Numerical weather prediction (NWP) models are commonly employed by the research community to gain better understanding into the genesis of the environmental forcing conditions leading to turbulence in the upper troposphere and lower stratosphere (UTLS), e.g., Sharman (2016). In particular, the use of grid nesting techniques has become notoriously popular in this context, allowing higher spatial fidelity in specific regions that support local turbulence mechanisms, while simultaneously capturing necessary large-scale forcing conditions within the coarser-resolution parent domains. The increase in computational power over the last decade is allowing mesoscale nested-NWP simulations reaching horizontal resolutions of $\Delta x \sim 1 \mathrm{~km}$ and beyond to be routinely exercised, and at which

\footnotetext{
D Denotes content that is immediately available upon publication as open access.
}

Corresponding author: Dr. Domingo Muñoz-Esparza, domingom@ ucar.edu some of the important gravity waves and turbulence instabilities start to be partially resolved. Examples of these types of NWP simulations include studies of clear-air turbulence (CAT) and waves (e.g., Feltz et al. 2009; Kim and Chun 2010; Mahalov et al. 2011; Trier et al. 2012), convectively induced waves and turbulence (e.g., Lane et al. 2003; Trier and Sharman 2009; Kim and Chun 2012; Barber et al. 2018; Zovko-Rajak et al. 2019) and turbulence associated with cirrus bands (e.g., Trier et al. 2010; Kim et al. 2014; Trier and Sharman 2016).

While fine-resolution mesoscale NWP simulations can more accurately represent important small-scale atmospheric processes, specific modeling aspects need to be better understood and taken into account at these scales. In this regard, the treatment of subgrid-scale (SGS) turbulence effects is of particular importance. Mesoscale NWP models assume that turbulence is fully parameterized, i.e., not resolved by the model grid, and therefore employ planetary boundary layer (PBL) parameterizations, which rely upon the horizontal homogeneity assumption (e.g., Stull 1988; Garratt 1994; Pielke 2013). However, when the horizontal grid spacing $\Delta x$ is fine enough (typically at $\sim 1 \mathrm{~km}$ ), some of these small-scale features become partly resolvable by the model, including gravity waves with short wavelengths $(\lambda \lesssim 10 \mathrm{~km})$, down to turbulence eddies $(\lambda \lesssim 1 \mathrm{~km})$. This aspect is undesired because it violates the horizontal homogeneity assumption employed by the SGS parameterizations (i.e., the one-dimensional PBL schemes), as the horizontal gradients at the grid scale become relevant and the resulting SGS turbulent fluxes need to be included in the closure scheme. This therefore results in a gray-zone type of modeling challenge specific to upper-level waves and 
turbulence, for which no parameterization currently exists that is applicable to these intermediate grid spacings (e.g., Wyngaard 2004; Chow et al. 2019).

Moreover, PBL schemes, as their name indicates, are typically developed with a focus on parameterizing turbulence effects in the atmospheric boundary layer (ABL). The ABL is subject to diurnal evolution influences through radiative heating/cooling at the surface, and these processes that produce ABL turbulence are different in nature from those acting in the UTLS. Nevertheless, PBL scheme diffusion is still routinely applied throughout the entire vertical extent of the NWP model domain. This is a modeling aspect that is often overlooked in studies focusing on upper-level flows, but that can potentially have a significant impact on the model results. Despite this fact, nested-NWP simulations have recently been exercised more frequently at $\Delta x \leq 1 \mathrm{~km}$ (e.g., Kim et al. 2014; Trier and Sharman 2016; Barber et al. 2018).

Herein we analyze the role of the SGS turbulence parameterization on the onset of three-dimensional resolved structures in fine-resolution nested-NWP simulations of $\Delta x=1 \mathrm{~km}$. We demonstrate these aspects by examining a specific CAT event that took place on 30 April 2017 in the northwestern portion of South Dakota, where there were many turbulence pilot reports (PIREPs) and in situ eddy dissipation rate observations that recorded significant elevated turbulence levels. The rest of the paper is organized as follows. Section 2 provides an overview of the selected case study, including specific details about model configuration. The details regarding SGS diffusion and the numerical experiments performed are provided in section 3. The sensitivity of UTLS waves to the particular PBL scheme used and large-scale forcing conditions is examined in sections 4 and 5. Statistical analysis of the different SGS diffusion treatments using very high-resolution large-eddy simulation (LES) as a reference is discussed in section 6. Finally, we recapitulate the main findings of the present work, provide some guidelines for model practitioners and identify a research path for the UTLS modeling community moving forward with high-resolution simulations.

\section{Case description and WRF Model simulations setup}

The selected case study focuses on a strong midlatitude cyclone exiting the Rocky Mountain region on 30 April 2017, which was associated with widespread turbulence across a significant portion of the contiguous United States (CONUS). To provide a general overview of the disruptiveness of this weather episode, in situ and PIREP turbulence reports in the form of eddy dissipation rate $\left(\mathrm{EDR}=\varepsilon^{1 / 3}, \mathrm{~m}^{2 / 3} \mathrm{~s}^{-1}\right)$ are presented for 1200-1700 UTC in Fig. 1. Within that relatively short time interval, there were a total of 447 turbulence reports, with 340 moderate turbulence $\left(0.22 \leq \mathrm{EDR}<0.34 \mathrm{~m}^{2 / 3} \mathrm{~s}^{-1}\right)$ and 13 severe $\left(E D R \geq 0.34 \mathrm{~m}^{2 / 3} \mathrm{~s}^{-1}\right.$ ) reports. ${ }^{1}$ As discussed in our companion paper (Trier et al. 2020), different mechanisms were responsible for the turbulence encounters in the two regions of more significant number of reports. In

\footnotetext{
${ }^{1}$ These thresholds for turbulence categories are based on Sharman et al. (2014).
}

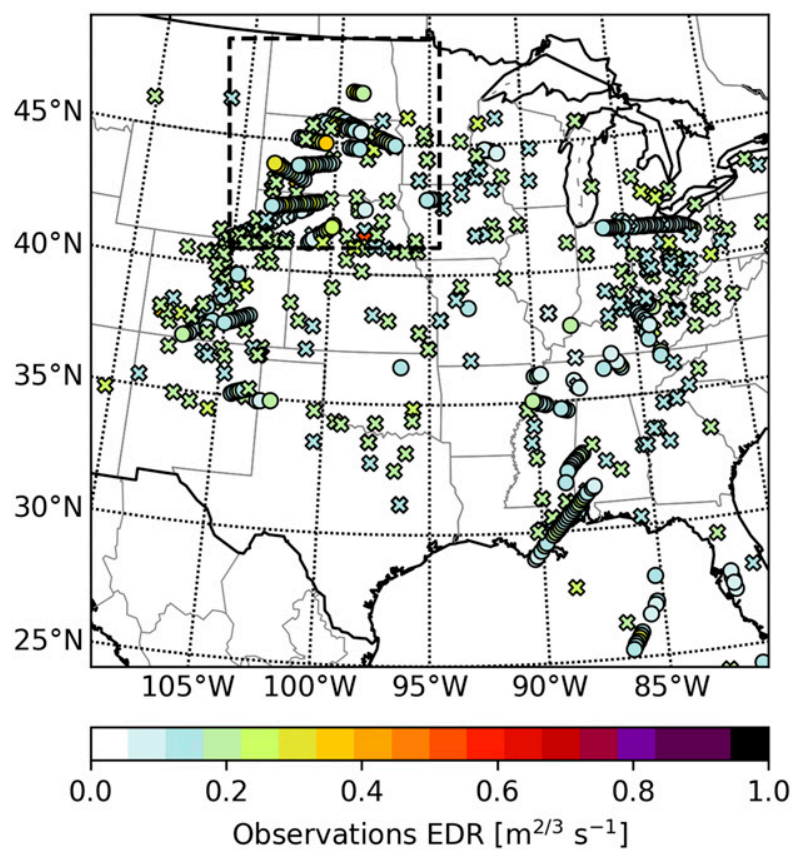

FIG. 1. Turbulence observations of eddy dissipation rate $\left(\mathrm{EDR}=\varepsilon^{1 / 3}\right)$ reported during the $5 \mathrm{~h}$ period from 1200 to 1700 UTC 30 Apr 2017. Circles denote automated in situ observations, while crosses correspond to PIREPs converted to EDR using the method described in Sharman et al. (2014). The extent of the figure represents the region covered by the parent domain (D01, $\Delta x=3.0 \mathrm{~km})$, with the one-way nested domain location indicated by the dashed-line rectangle (D02, with $\Delta x=1.0 \mathrm{~km}$ in all cases but the LES case, where $\Delta x=250 \mathrm{~m})$.

Texas, a short-lived turbulence event was found to be related to lower-stratospheric gravity waves of $\lambda \sim 100 \mathrm{~km}$ in the exit region of a UTLS jet streak. Over the South Dakota region, more persistent and widespread turbulence occurrences were attributed to Kelvin-Helmholtz instability (KHI) leading to overturning waves of much shorter wavelengths $(\lambda=5-10 \mathrm{~km})$, developing in horizontal locations above and beneath the convectively enhanced UTLS jet. For the present analysis of the model SGS aspects targeted herein, we focus on the latter event.

Simulations with the Advanced Research WRF Model (Skamarock et al. 2008; Skamarock and Klemp 2008) version 4.0.1 are performed to investigate the role of SGS turbulence parameterization on modeled UTLS wave and turbulence activity. The model setup consists of two one-way nested domains with $970 \times 935$ and $901 \times 901$ grid points in the zonal and meridional directions, with horizontal resolutions of 3 and $1 \mathrm{~km}$, respectively (Fig. 1). For the vertical grid, the domain top is placed at $25 \mathrm{hPa}$, and 150 vertical levels are used, with a uniform vertical spacing of $\Delta z \approx 100 \mathrm{~m}$ beneath $12 \mathrm{~km}$, which is progressively stretched above. Such vertical spacing is sufficiently fine to ensure grid convergence of the numerical results (Skamarock et al. 2019).

Physical parameterizations used include the longwave and shortwave RRTMG model (Iacono et al. 2008) and the 
Thompson microphysics scheme (Thompson et al. 2008). The Noah-MP land surface model (Niu et al. 2011) was used for the land surface coupling, while the surface-layer parameterization option was set according to the selected PBL scheme, with all of them based on the Monin-Obukhov similarity theory (Monin and Obukhov 1954). A Rayleigh damping layer with a coefficient of $0.2 \mathrm{~s}^{-1}$ was used in the upper $7.0 \mathrm{~km}$ of the domain to minimize reflection of spurious waves off the model top (Klemp et al. 2008). To improve the representation of small-scale features, we employ the hybrid-order advection scheme from Kosović et al. (2016), which increases the effective resolution of WRF by almost a factor of $2(\approx 4-5 \Delta x)$ without adding computational cost. This is achieved by reducing the numerical diffusion component inherent to the odd-order scheme. The hybrid-order scheme has been satisfactorily employed to perform both mesoscale and large-eddy simulations using the WRF Model (Muñoz-Esparza et al. 2018a,b). In addition, this scheme has also been shown by Skamarock and Gassmann (2011) to provide higher accuracy than the corresponding higher oddorder scheme.

Initial and boundary conditions were specified from the National Centers for Environmental Prediction (NCEP) Final Operational Global (FNL) analysis, with a horizontal resolution of $1.0^{\circ}$ and available every $6 \mathrm{~h}$. These FNL analyses were linearly interpolated in time to provide smoothly varying lateral boundary conditions every $1 \mathrm{~h}$. All simulations were initialized at 1800 UTC 29 April 2017 and run for $24 \mathrm{~h}$, with the initial $12 \mathrm{~h}$ serving as model spinup, and only the last $12 \mathrm{~h}$ (0600-1800 UTC) were analyzed using $30 \mathrm{~min}$ model output. The only exception is the WRF-LES, where the nested domain was initialized at a later stage (0600 UTC 30 April), given the large computational cost of that simulation with $\Delta x=250 \mathrm{~m}$. Nevertheless, after $6 \mathrm{~h}$, the additional small-scale energy content was fully spun up.

\section{Parameterization of subgrid-scale mixing and numerical experiments}

As mentioned in the previous section, mesoscale NWP models employ one-dimensional (1D) PBL schemes, which provide vertical diffusion that attempts to represent the effect of fully parameterized SGS turbulence effects on the resolved dynamics through divergence of parameterized SGS turbulence fluxes:

$$
\tau_{\phi 3}=-K_{\phi}\left(\frac{\partial \phi}{\partial z}\right)+\overline{w^{\prime} \phi^{\prime}}{ }_{z_{i}},
$$

for $\phi=u, v, \theta, q$, which correspond to the zonal and meridional velocity components, potential temperature, and moisture species and other scalars, respectively, and where the subindex " 3 " denotes the vertical direction ( $z$ coordinate). This countergradient approach utilizes an eddy diffusivity $K_{\phi}$ and in a general form includes terms for nonlocal transport due to large coherent eddies $\gamma_{\mathrm{nl}}$ and a correction for entrainment processes at the top of the boundary layer height $z_{i}$ represented by the term $\overline{w^{\prime} \phi^{\prime}}{ }_{z_{i}}$.

A variety of $1 \mathrm{D}$ PBL schemes, hereafter referred to as simply PBL schemes, are available for use in the WRF community model. Three of the most commonly used schemes in WRF are the Yonsei University (YSU; Hong et al. 2006), the Mellor-Yamada-Janjić (MYJ; Janjić 1994) and the MellorYamada-Nakanishi-Niino (MYNN; Nakanishi and Niino 2004; Olson et al. 2019b) schemes. The main difference among these schemes concerns how they parameterize the eddy diffusivities, in particular the momentum diffusivity $K_{m}$. In the case of first-order schemes, such as YSU, the eddy diffusivity of momentum is parameterized using an analytical profile, commonly referred to as $K$-profile approach. For vertical levels above the boundary layer height, and which are most relevant for the current study, the formulation from Louis (1979) is used, which is a function of a mixing length $\ell$ and a stability correction function $S_{m}$ that depends on the Richardson number, $\mathrm{Ri}=$ $g \Delta z \Delta \theta_{v} / \theta_{v}(\Delta \mathbf{u})^{2}$,

$$
K_{m}=\ell^{2} S_{M} \frac{\partial U}{\partial z}
$$

In contrast, $\mathrm{MYJ}$ and $\mathrm{MYNN}^{2}$ are 1.5 -order schemes that solve a prognostic equation for SGS turbulent kinetic energy (TKE), $e$, which is used to parameterize the eddy diffusivities:

$$
K_{m}=\ell S_{M} e^{1 / 2}
$$

Note that in TKE-based PBL schemes, the entire vertical domain column is identically treated (i.e., there is no distinct formulation for free troposphere and stratosphere). In both Eqs. (2) and (3), the master length scale is parameterized similarly, as the harmonic mean of several length-scale contributions:

$$
\frac{1}{\ell}=\frac{1}{\ell_{s}}+\frac{1}{\ell_{t}}+\frac{1}{\ell_{b}},
$$

representing specific terms accounting for surface, turbulence, and buoyancy effects. In this regard, YSU only considers $\ell_{s}=\kappa z$, where $\kappa$ is the von Kármán constant, and a fixed $\ell_{t}=150 \mathrm{~m}$ (asymptotic limit), known as Blackadar formula (Blackadar 1962). These two length scales are also used by MYJ, which prescribes $\ell_{b}$ as a function of the integrated $e$ weighted by distance from the surface. MYNN further includes stability-dependence effects on $\ell_{s}$, uses an $\ell_{t}$ similar to MYJ, and incorporates another contribution from buoyancy effects (bl_mynn_mixlength $=2$, see full details of the length-scale implementation in Olson et al. 2019a). Also, note that the stability function in Eq. (3) differs between MYJ and MYNN. Finally, heat, moisture and other scalar eddy diffusivities are derived for each scheme by employing a turbulent Prandtl number approach, $K_{h}=\operatorname{Pr}^{-1} K_{m}$.

For the assessment of the different $1-\mathrm{km}$ runs presented in section 6 we utilize nested high-resolution large-eddy

\footnotetext{
${ }^{2}$ For the control experiments, we used the standard MYNN scheme implementation (bl_mynn_edmf=0), not the recent extension that blends it with the eddy-diffusivity mass-flux (EDMF) scheme.
} 
TABLE 1. List of simulations indicating the PBL scheme option applied in each of the two domains. The parent domain, D01, always utilizes $\Delta x=3.0 \mathrm{~km}$. All the cases use the same vertical grid spacing, consisting of 150 vertical levels with a uniform $\Delta z \approx 100 \mathrm{~m}$ for $z<12 \mathrm{~km}$, and progressively stretched above. All of the numerical experiments cover the same spatial extent (see Fig. 1) and feedback is one way. The suffix "md" stands for modified diffusion, where the PBL scheme is modified to remove its vertical diffusion for $z>1.2 z_{i}$. Four variants of the MYNN implementation in WRF were exercised, depending on the blending with the eddy-diffusivity mass-flux (EDMF) scheme and the option to calculate the master length scale: MYNN (bl_mynn_edmf $=0$, bl_mynn_mixlength $=2$, control scheme configuration), MYNNO (bl_mynn_edmf $=0$, bl_mynn_mixlength $=0$ ), MYNN1 (bl_mynn_edmf $=0$, bl_mynn_mixlength $=1$ ), and MYNNEDMF (bl_mynn_edmf=1, bl_mynn_mixlength=2).

\begin{tabular}{lllc}
\hline \hline \multicolumn{1}{c}{ Simulation name } & $\begin{array}{c}\text { D01 PBL } \\
\text { scheme }\end{array}$ & \multicolumn{1}{c}{$\begin{array}{c}\text { D02 PBL } \\
\text { scheme }\end{array}$} & $\begin{array}{c}\text { D02 } \\
\Delta x(\mathrm{~km})\end{array}$ \\
\hline MYNN (S1-MYNN) & MYNN & MYNN & 1.0 \\
MYJ & MYJ & MYJ & 1.0 \\
YSU & YSU & YSU & 1.0 \\
S1-MYJ & MYNN & MYJ & 1.0 \\
S1-YSU & MYNN & YSU & 1.0 \\
S1-MYNNmd & MYNN & MYNNmd & 1.0 \\
S1-MYJ & MYNN & MYJmd & 1.0 \\
S1-YSU & MYNN & YSUmd & 1.0 \\
MYNN0 & MYNN0 & MYNN0 & 1.0 \\
MYNN1 & MYNN1 & MYNN1 & 1.0 \\
MYNN-EDMF & MYNN-EDMF & MYNN-EDMF & 1.0 \\
S1-MYNN0 & MYNN & MYNN0 & 1.0 \\
S1-MYNN1 & MYNN & MYNN1 & 1.0 \\
S1-MYNN-EDMF & MYNN & MYNN-EDMF & 1.0 \\
LES & MYNN & LES & 0.25 \\
\hline
\end{tabular}

simulation (LES) as a reference. For the WRF-LES, the same model setup as in the mesoscale NWP simulations is used (e.g., domain boundaries and physical parameterizations). However, for the LES domain, the horizontal grid spacing is $\Delta x=250 \mathrm{~m}$, and in contrast to the PBL schemes, employs a three-dimensional SGS closure, thus providing parameterized diffusion due to small eddies in the three spatial directions:

$$
\tau_{i j}=-2 K_{m} S_{i j}
$$

where $S_{i j}=0.5\left(\partial u_{i} / \partial x_{j}+\partial u_{j} / \partial x_{i}\right)$ is the strain-rate tensor. In Eq. (5) $K_{m}$ is parameterized similarly to Eq. (3) by employing a prognostic equation for SGS TKE (Lilly 1966, 1967; Deardorff 1980). In the LES regime, the stability correction function is a constant and equal to 0.1 , as recommended by Moeng and Wyngaard (1988), and the master length scale becomes the grid size, $\ell=\sqrt[3]{\Delta x^{2} \Delta z}$, with a correction to account for the reduction in $\ell$ under stably stratified conditions.

To untangle the PBL scheme influence on both large-scale meteorological conditions and small-scale wave and turbulence activity, we perform a series of numerical experiments varying the SGS diffusion option, as indicated in Table 1 . The first set of experiments consists of three standard WRF simulations in which both the 3 - and 1-km domains utilize the same PBL scheme (section 4). Then, we use the MYNN scheme in each parent domain but vary the PBL parameterization in the nested domains, indicated by the prefix "S1," which are analyzed in section 5. The reference WRFLES also employs the MYNN scheme in the parent 3-km domain, presented in section 6 . As will be further discussed later in the manuscript (section 5), we modify the three PBL schemes exercised herein such that the SGS diffusion is removed above the ABL. For these experiments, labeled with the suffix "md" denoting modified diffusion, the PBL scheme vertical mixing only operates where $z \leq 1.2 z_{i}$. A progressive linear reduction of $\tau_{\phi 3}$ is applied in the $1.0<$ $z / z_{i} \leq 1.2$ range to avoid strong discontinuities in the SGS diffusion.

\section{Sensitivity to PBL scheme formulation}

In this section we analyze the behavior of the $1-\mathrm{km}$ nested simulations that adopt the standard approach used in WRF (i.e., all domains use the same PBL scheme). Our case study of UTLS turbulence occurs within a synoptic-scale baroclinic wave cyclone. The overall accuracy of this simulated weather event is conveyed through comparisons of the simulated spatial patterns of the D01 maximum reflectivity in each vertical column with corresponding radar observations at 1500 UTC (Fig. 2d). Here, simulations using each of the three different PBL schemes, MYNN (Fig. 2a), MYJ (Fig. 2b) and YSU (Fig. 2c) compare very well to the observed NEXRAD radar mosaics of maximum reflectivity (MREF). While some discrepancies in the actual reflectivity magnitude are expected due to the differences between the actual radar retrievals and the diagnosed reflectivity field in WRF, the overall pattern of the synoptic-scale precipitation system is well captured in WRF using each of the three PBL schemes. Although the simulations tend to overpredict the instantaneous precipitation intensity along the northwestern portion of the cyclone, nevertheless, the timing of the system and the spatial pattern of precipitation is accurately simulated near our region of interest where UTLS turbulence occurs in South Dakota throughout the simulation period.

For a more quantitative assessment of the skill of the model in reproducing the key meteorological conditions during this turbulence episode, we compare the WRF Model results at 1200 UTC to three available National Weather Service (NWS) soundings from within the boundaries of domain D02 (see Fig. 3). These soundings include Aberdeen, South Dakota (KABR); Bismarck, North Dakota (KBIS); and Rapid City, South Dakota (KUNR), whose geographic locations are indicated in Fig. 4a. The KABR sounding contains a strong jet (peak speed $\approx 75 \mathrm{~m} \mathrm{~s}^{-1}$ ) centered at $z \approx 11.5 \mathrm{~km} \mathrm{MSL}$, which is enhanced by the convectively induced UTLS outflow, and is accurately captured by all three WRF simulations (both in terms of its strength and location). In addition, the simulated wind direction and potential temperature profiles are in very good agreement with the sounding data. Similar performance is found for KBIS, $235 \mathrm{~km}$ to the northwest, where a somewhat weaker jet with maximum speed of $\approx 50 \mathrm{~m} \mathrm{~s}^{-1}$ occurs. At this location, the spread among model simulations is larger, with MYNN and MYJ overpredicting the strength of the jet and YSU slightly underpredicting its strength, and locating its peak 
(a) MYNN

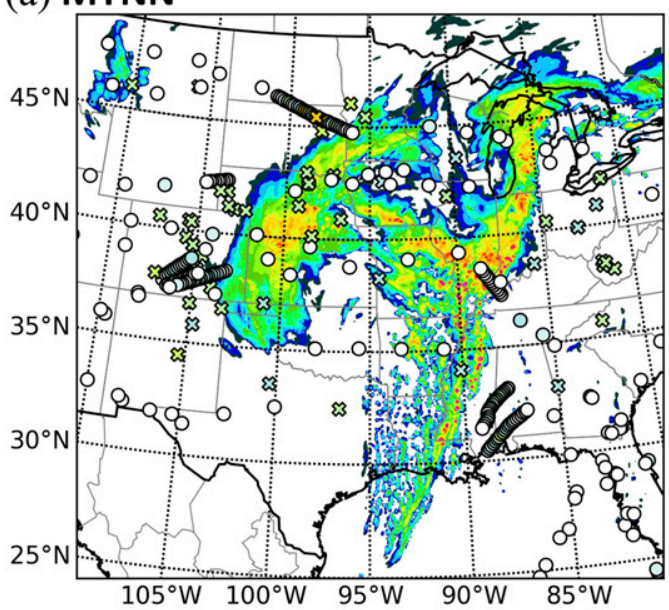

(c) YSU

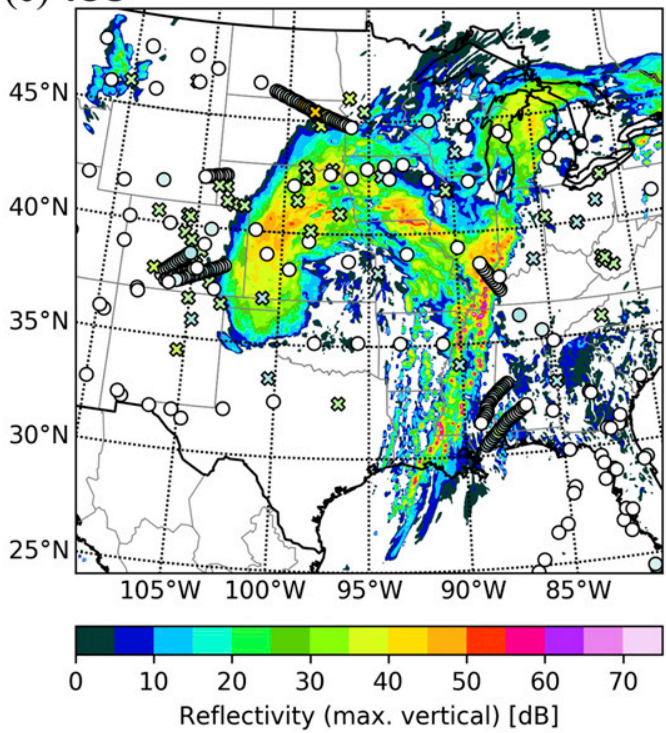

(b) MYJ

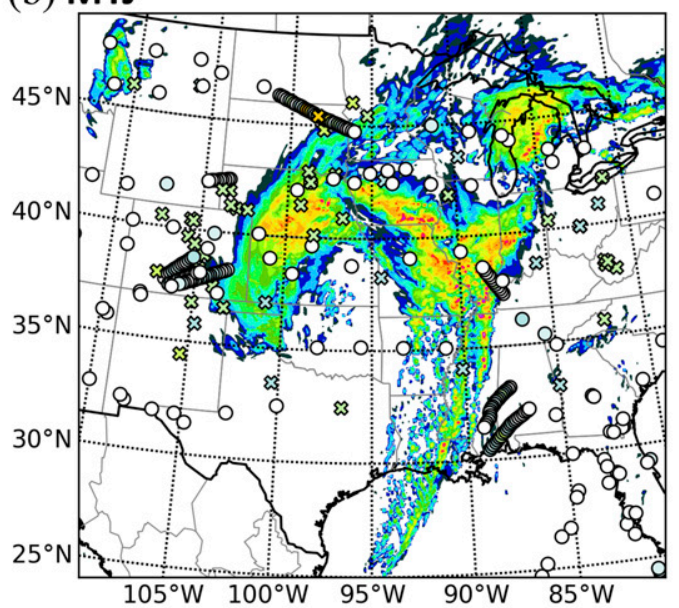

(d) Mosaic Radar Reflectivity (MREF)

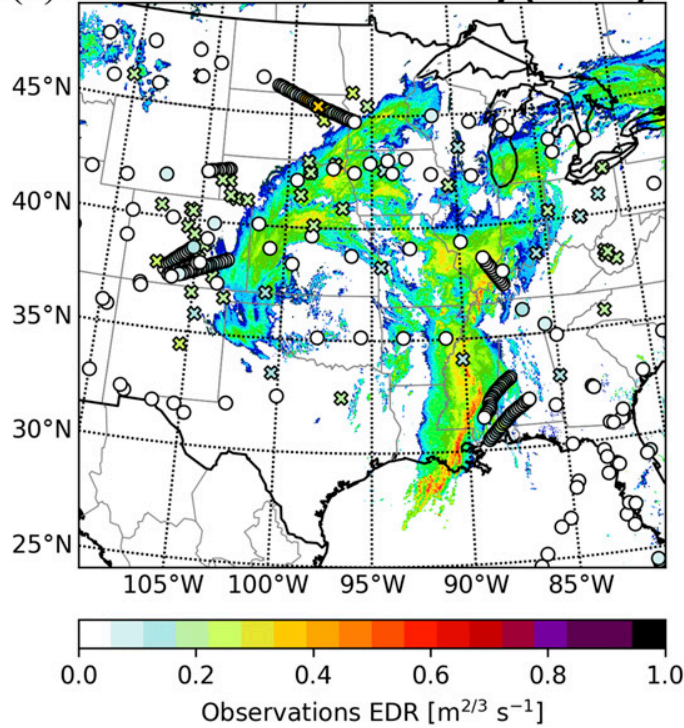

FIG. 2. Comparison of modeled maximum reflectivity in the vertical column for the MYNN, MYJ, and YSU simulations on the D01 parent domains $(\Delta x=3 \mathrm{~km})$ and the observed NSSL radar reflectivity composite (https://www.nssl.noaa.gov/projects/mrms/) at 1500 UTC 30 Apr 2017. Turbulence EDR reports in the form of in situ (circles) and PIREPs (crosses) within a $\pm 30 \mathrm{~min}$ time window and $\pm 1000 \mathrm{ft}(\sim 300 \mathrm{~m})$ in height are overlaid.

speeds at a lower height by $\approx 800 \mathrm{~m}$. At KUNR, located to the southwest and closer to the synoptic trough axis, wind speeds are significantly weaker in the observations compared to KABR and KBIS, and are slightly overpredicted in the three simulations. This comparison to available sounding profiles provides further confidence in the ability of the performed simulations to reasonably capture the relevant wind and thermodynamic profiles that influence the development of UTLS turbulence over the region.

To provide further insight into the differences arising from the different SGS diffusion treatments, horizontal cross sections at $z=7.0 \mathrm{~km}$ MSL for two different times, 1600 and 1700 UTC, are presented in Fig. 4. Wind barbs are plotted together with contours of vertical velocity and the cloud boundary isoline corresponding to a total cloud condensate threshold of $q_{t}=0.005 \mathrm{~g} \mathrm{~kg}^{-1}$ (including water vapor, rain, snow, graupel, and ice hydrometeors). Turbulence observations within a \pm 30 min time interval and $\pm 1000 \mathrm{ft}$ $(\sim 300 \mathrm{~m})$ in height are included for reference. Here, significant differences are found among the different PBL schemes. MYJ contains a narrow several-hundred-kilometer-long swath of wavelike vertical perturbations located approximately $200 \mathrm{~km}$ west of the synoptic cloud boundary, with wave amplitudes as large as $5 \mathrm{~m} \mathrm{~s}^{-1}$.

These vertical velocity perturbations correspond to vertically trapped gravity waves as demonstrated by an analysis of the Scorer parameter in Trier et al. (2020). In contrast, neither the MYNN nor the YSU schemes produce any clearly 

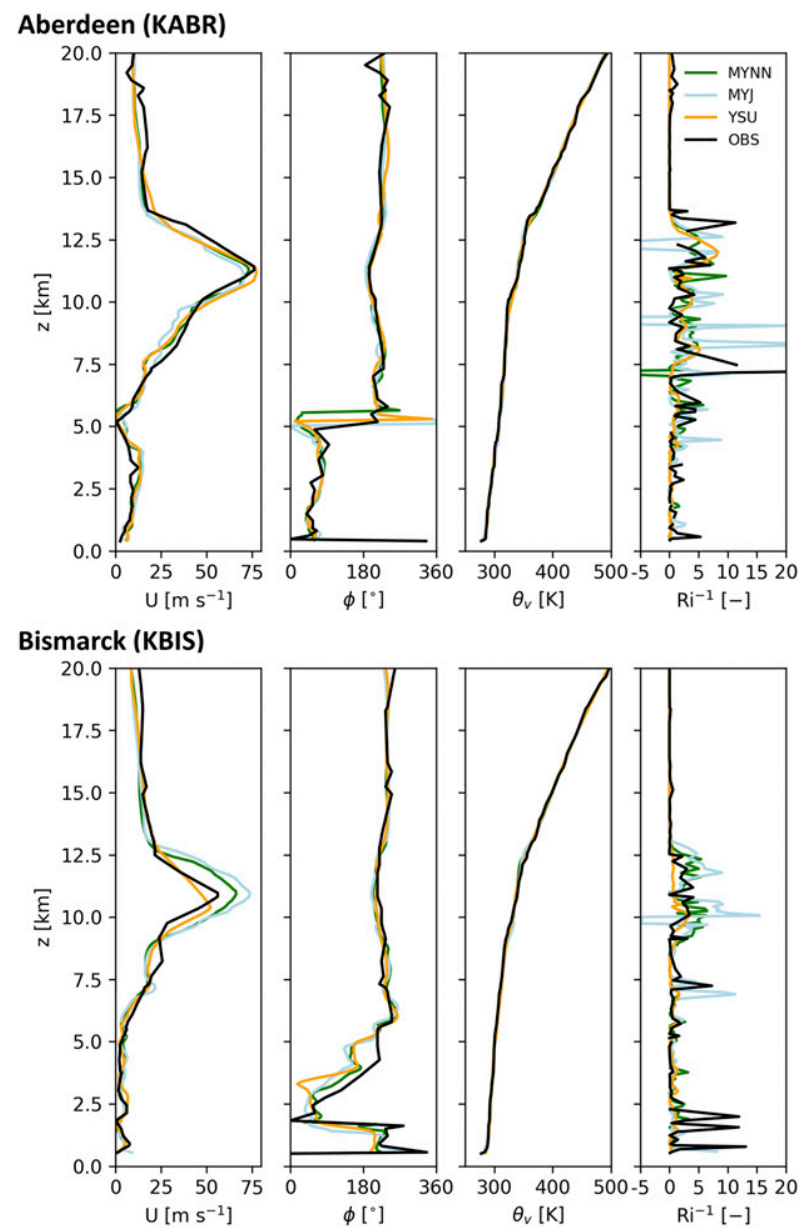

Rapid City (KUNR)
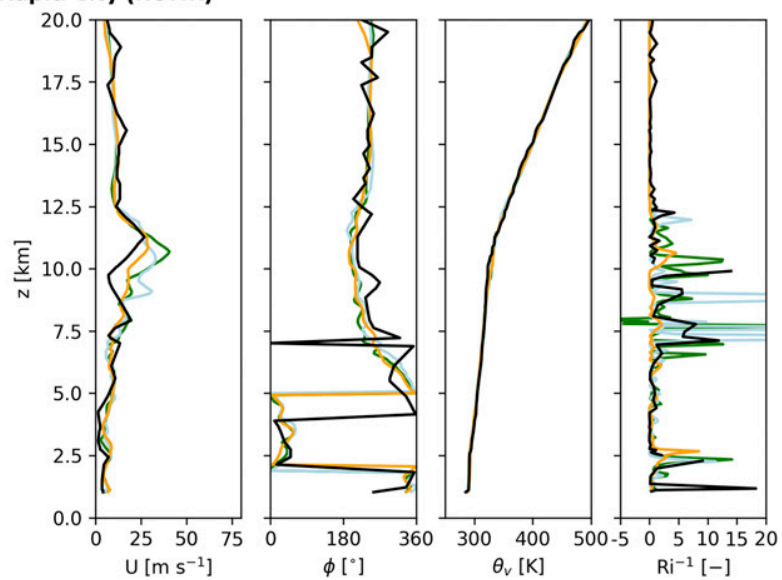

FIG. 3. Sounding observations of (top to right) wind speed, direction, potential temperature, and inverse Richardson number at 1200 UTC 30 Apr 2017 (black), compared to the $1 \mathrm{~km}$ D02 results from the MYNN (green), MYJ (light blue), and YSU (orange) simulations. All available soundings within the domain D02 are included, namely, (top) Aberdeen, (middle) Bismarck, and (bottom) Rapid City. The location of these three soundings is indicated by black triangles in Fig. 4a. discernible wave activity at $7 \mathrm{~km}$ MSL or higher altitudes at the current or subsequent times. Both of these schemes show attempts to resolve some wave activity of reduced amplitude and extent within the region where MYJ displays more pronounced wave activity at both 1600 and 1700 UTC. Moreover, MYJ also contains more widespread significant vertical velocity perturbations farther east, within the cloud boundary of the synoptic weather system compared to the other two PBL schemes (Fig. 4). These results provide a clear example of the impact of PBL scheme diffusion in these high-resolution mesoscale simulations, an aspect that, to our knowledge, has been overlooked in numerical studies of UTLS turbulence. However, there can be an indirect effect from SGS diffusion on the background large-scale vertical shear and static stability, which could contribute to the onset of the smallscale waves in the MYJ simulation, and that can be seen in the comparison of the simulated and observed 1200 UTC soundings in Fig. 3. In particular, the inverse Richardson number profiles show a more frequent exceedance of $\mathrm{Ri}^{-1}=4.0$, indicative of background atmospheric conditions conducive to the development of shear instabilities. We address the contribution from background atmospheric conditions in the next section.

\section{Sensitivity to large-scale forcing and modified PBL diffusion}

As already discussed, we performed a series of nested simulations in which the parent domains D01 all employed the MYNN scheme, and that therefore provided the exact same forcing on the lateral boundaries of the D02 nested 1$\mathrm{km}$ domain (simulation names indicated by the "S1" prefix). The simulated 1600 UTC horizontal cross sections at $z=$ $7.0 \mathrm{~km}$ MSL for D02 of the different nested simulations are shown in Fig. 5. Interestingly, the strength of the wave activity in S1-MYJ (Fig. 5c) is larger than in MYJ (Fig. 4c). Also, S1-YSU (Fig. 5e) exhibits a more coherent wave signal that significantly grows in spatial extent between 1600 and 1700 UTC (not shown), which is not evident in YSU (Figs. 4e,f). These differences point to the role of PBL scheme diffusion in affecting resolved gradients of velocity components and potential temperature at larger scales, a prerequisite for the onset and development of these wave instabilities. When examining the cases with modified diffusion, we found the three simulations to display unequivocal waves in the clear-air region to the west of the cloud edge. The S1-MYNNmd simulation (Fig. 5b) displays the waves clearly, while the original S1-MYNN (same as MYNN) does not (Fig. 5a). In this particular case, the only difference between S1-MYNN and S1-MYNNmd simulations is the removal of the parameterized SGS vertical mixing in the S1-MYNNmd simulation for $z>1.2 z_{i}$. Such behavior exposes the overly dissipative nature of the MYNN scheme above the ABL compared to MYJ, which like MYNN employs 1.5-order SGS TKE-based formulations.

Overall, the corresponding modified diffusion runs provide more consistent results than their counterparts with PBL-scheme mixing throughout the model depth, and allow 
(a) MYNN [1600 UTC]

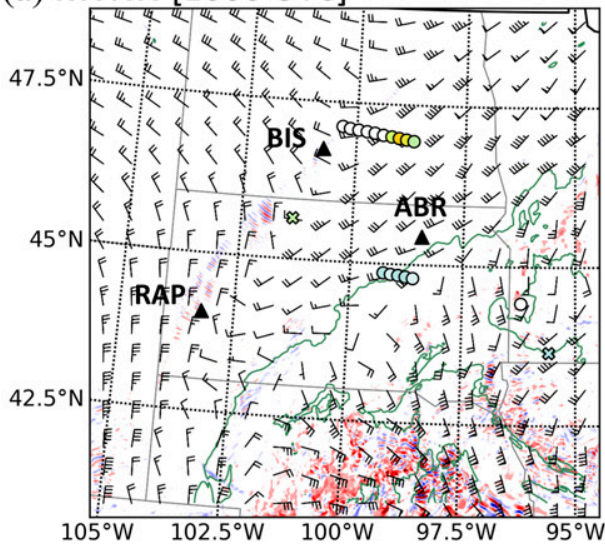

(c) MYJ [1600 UTC]

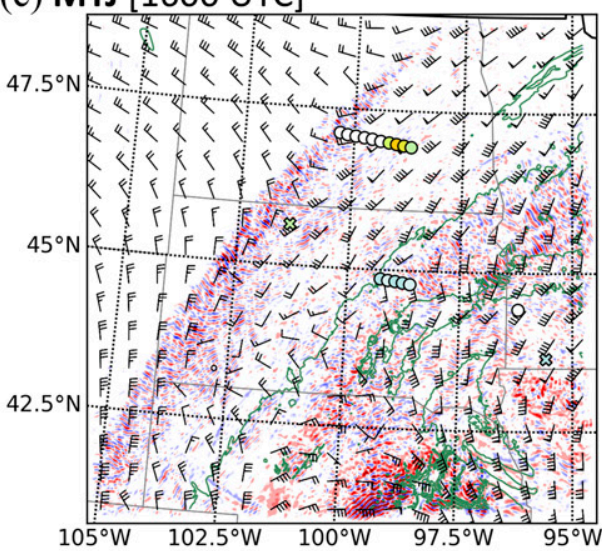

(e) YSU [1600 UTC]

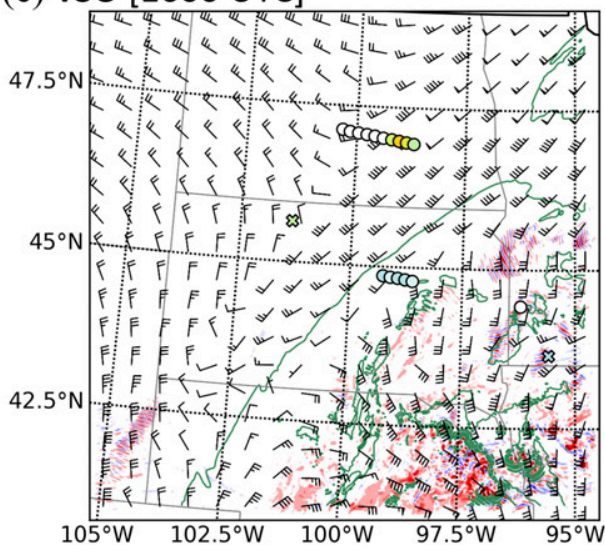

(b) MYNN [1700 UTC]

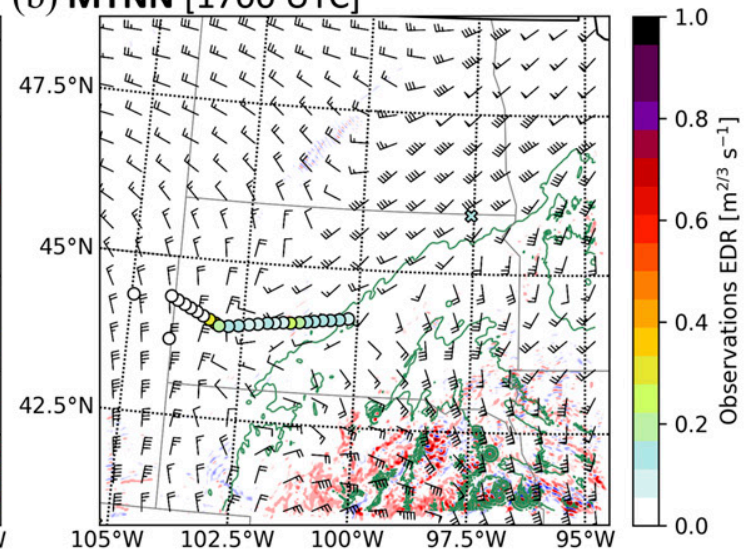

(d) MYJ [1700 UTC]

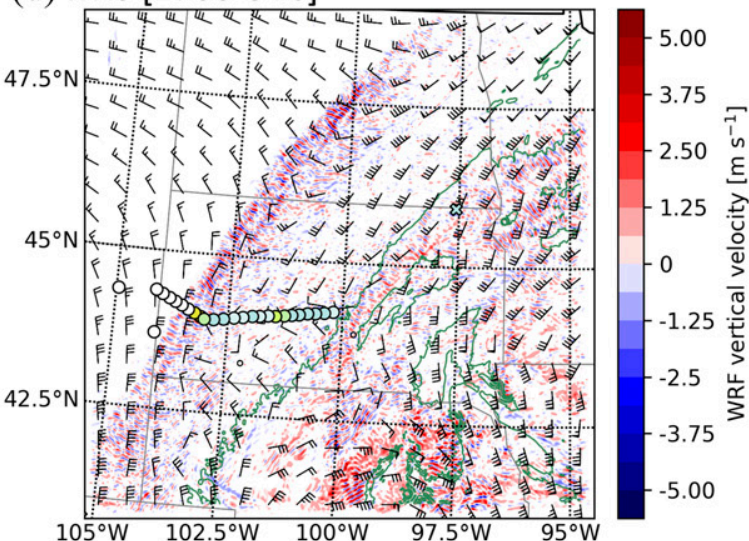

(f) YSU [1700 UTC]

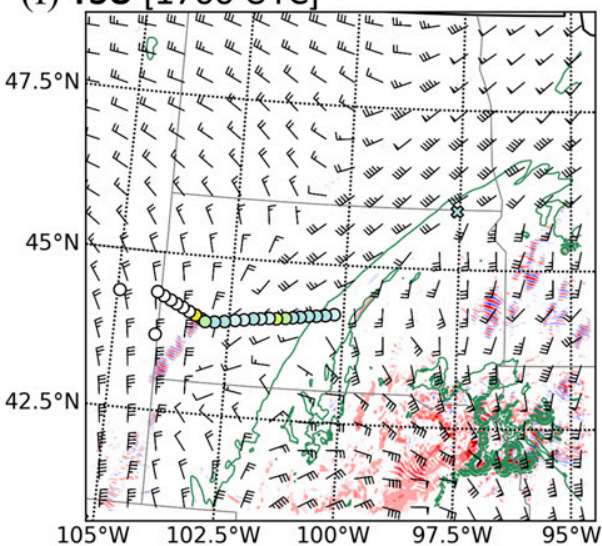

FIG. 4. Horizontal cross sections of model vertical velocity contours, wind barbs, and cloud boundary corresponding to a total cloud condensate threshold (green line) of $q_{t}=0.005 \mathrm{~g} \mathrm{~kg}^{-1}$ (including water vapor, rain, snow, graupel, and ice hydrometeors). Cross sections are taken at $z=7.0 \mathrm{~km}$ MSL for the (a),(b) MYNN, (c),(d) MYJ, and (e),(f) YSU simulations on domain D02 $(\Delta x=1.0 \mathrm{~km})$ at two times: (left) 1600 and (right) 1700 UTC. Turbulence observations within a $\pm 30 \mathrm{~min}$ time interval and $\pm 1000 \mathrm{ft}(\sim 300 \mathrm{~m})$ in height are included for reference, with circles denoting in situ EDR and crosses denoting PIREPs. The black triangles indicate the location of the soundings: Aberdeen (ABR), Bismarck (BIS), and Rapid City (RAP).

development of finer-scale features, owing to a reduced level of diffusion that only arises from other explicit filters in WRF (e.g., 2D Smagorinsky, divergence damping, acoustic off-centering) and the implicit filtering inherent to the finite-difference schemes employed to discretize the advection terms in the governing equations. Among these diffusion sources, it has recently been found by Skamarock et al. (2019) that the PBL scheme dominates over other 
(a) S1-MYNN

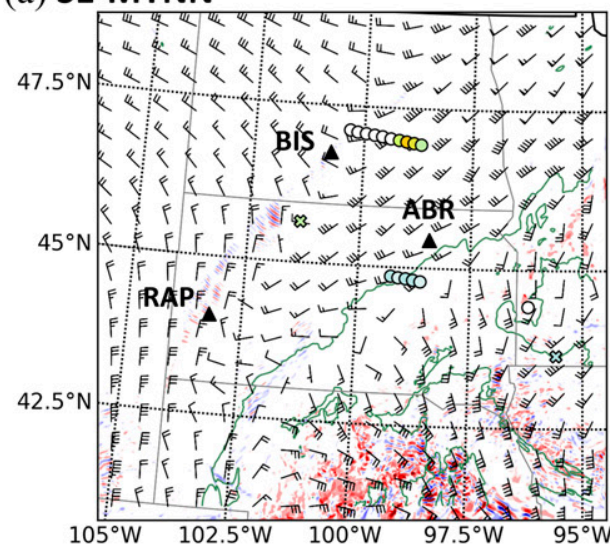

(c) S1-MYJ

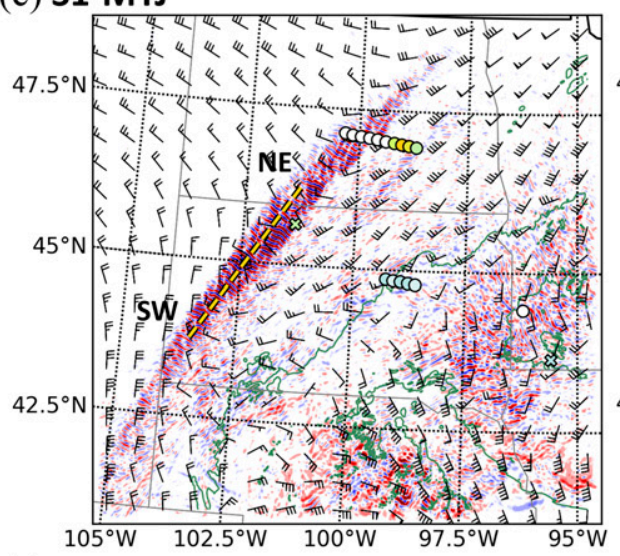

(e) S1-YSU

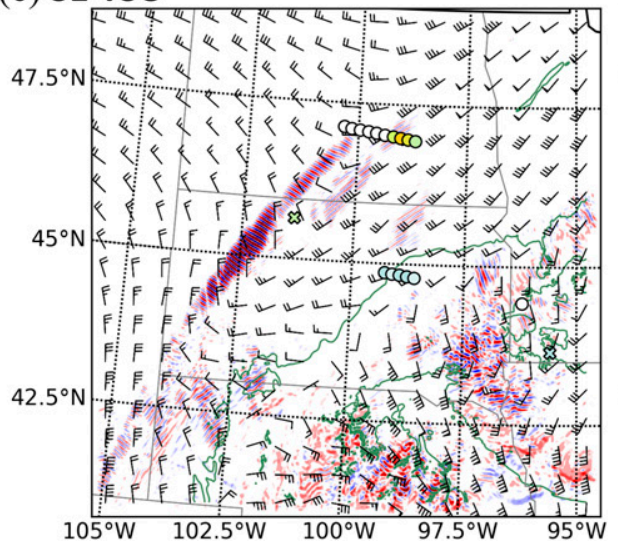

(b) S1-MYNNmd

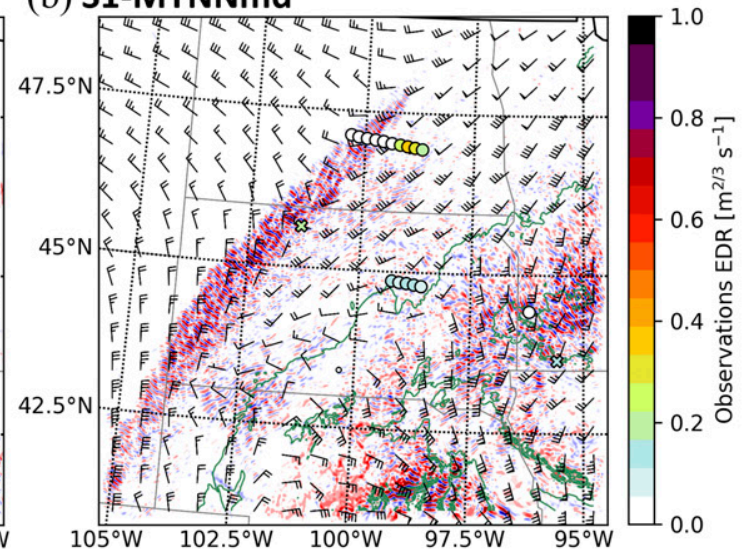

(d) S1-MYJmd

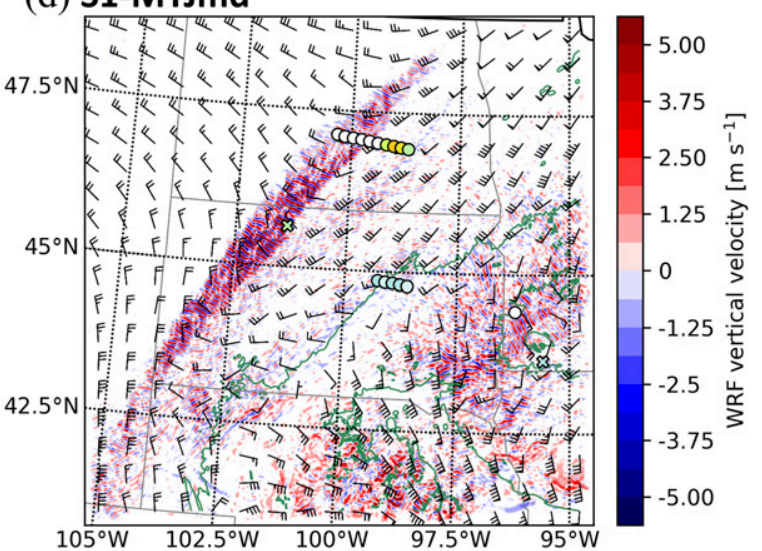

(f) S1-YSUmd

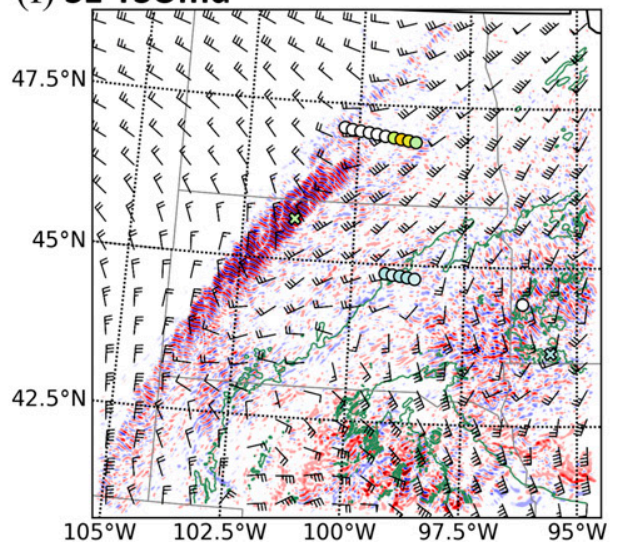

FIG. 5. Horizontal cross sections of model vertical velocity contours, wind barbs, and cloud boundary corresponding to a total cloud condensate threshold (green line) of $q_{t}=0.005 \mathrm{~g} \mathrm{~kg}^{-1}$ (including water vapor, rain, snow, graupel, and ice hydrometeors). Cross sections are taken at $z=7.0 \mathrm{~km}$ MSL for the (a) S1-MYNN, (b) S1MYNNmd, (c) S1-MYJ, (d) S1-MYJmd, (e) S1-YSU, and (f) S1-YSUmd simulations on domain D02 $(\Delta x=1.0 \mathrm{~km})$ at 1600 UTC. The "S1" simulations all use the standard MYNN scheme on the parent domain $(\Delta x=3.0 \mathrm{~km})$. Turbulence observations within a $\pm 30 \mathrm{~min}$ time interval and $\pm 1000 \mathrm{ft}(\sim 300 \mathrm{~m})$ in height are included for reference, with circles denoting in situ EDR and crosses denoting PIREPs. The black triangles in (a) indicate the location of the soundings: Aberdeen (ABR), Bismarck (BIS), and Rapid City (RAP). The dashed SW-NE line in (c) indicates the transect for the vertical cross sections in Fig. 6. 
diffusion terms. ${ }^{3}$ More consistent results among simulations is an expected outcome in the modified diffusion experiments, and reveals the lack of consistency and strong sensitivity to the $1 \mathrm{D}$ PBL scheme formulation at $1 \mathrm{~km}$ horizontal resolutions.

The impact of the PBL scheme is illustrated further by the vertical cross sections (Fig. 6) along the wave SW-NE transect (indicated in Fig. 5c). The trapped gravity waves that we have been focusing on in our analysis impinge on a layer of reduced $\mathrm{Richardson}$ number below $\mathrm{Ri}=0.25$, indicated by the yellow isolines. Overturning isentropes as the result of a $\mathrm{KHI}$ are present within a layer of reduced $\mathrm{Ri}$, which led to turbulence generation at these higher heights, and that is consistent with the reported observations (Fig. 1). In all cases, a few thin unstable layers where $\mathrm{Ri}<0.25$ are found in a vertical layer approximately located at $z=7.5-11.5 \mathrm{~km}$ MSL, and that contains intervening layers that are dynamically stable. However, SGS mixing in the S1-MYNN run inhibits development of the waves beneath. The $90^{\circ}$ phase shift between $\theta$ and $w$ present in all of the other cases indicates that these are gravity waves, which are found to be either required for small-scale turbulence to develop aloft after breaking near critical levels or a response to KHI at levels below.

In general, the structure of the simulated waves is dramatically affected by the PBL scheme, differing in their vertical extent of propagation, wavelength, and amplitude among the SGS mixing formulations. As an example, the S1-YSU simulation depicts waves of a more coherent vertical structure compared to the other simulations, which are capable of penetrating beyond the troposphere and produce an impact on the lower stratosphere, as seen from the disturbances in the potential temperature isentropes. Like in the YSU simulations (Figs. 6e,f), there is also evidence of vertically propagating gravity waves above the overturning billows in the MYJ simulations (Figs. 6c,d), as discussed more extensively in Trier et al. (2020).

Further understanding of the impact of the SGS mixing treatment is illustrated by quantitatively examining the differences among the nested $1 \mathrm{~km}$ simulation results for the horizontal velocity differences at $z=7.0 \mathrm{~km} \mathrm{MSL}$ and the wind shear differences over a 2-km-deep layer between 6.0 and $8.0 \mathrm{~km}$ MSL, $\Delta U_{2 \mathrm{~km}}$ (Fig. 7). The simulation used for reference is S1-MYNN, which did not produce waves, and the true magnitude wind barbs (not the differences) are plotted in blue in that panel for reference (Fig. 7a). In the northwest portion of the domain, characterized by quiescent clear-air conditions in the absence of gravity waves or moist convection, the PBL scheme diffusion option makes no difference to the local winds or $\Delta U_{2 \mathrm{~km}}$, as can be seen from the lack of color contours and the presence of white circles corresponding to zero wind speed magnitude and direction differences. All the

\footnotetext{
${ }^{3}$ These results were obtained with the Model for Prediction Across Scales (MPAS), which has a similar dynamical core and physical parameterizations to those in WRF. In the reference study the YSU scheme was utilized.
}

comparisons consistently reveal that gravity wave activity develops in concert with enhanced wind shear, with increased $\Delta U_{2 \mathrm{~km}}$ occurring over a region surrounding the environment where wave activity is present in the clear air in all the simulations with $\Delta U_{2 \mathrm{~km}} \approx 10-20 \mathrm{~m} \mathrm{~s}^{-1}$. Within the cloud region, there are significant differences in both local winds and vertical wind shear in all cases, indicating how the presence of moist convection can amplify the nonlinearities in NWP models. The S1-MYNNmd simulation (Fig. 6b) further supports this notion by displaying a region of no differences with respect to S1-MYNN, toward the southeast corner of the domain, only for the locations within clear-air conditions, even while surrounded by a cloud envelope.

As discussed in this and the previous section, the MYNN scheme hinders the development of wave activity compared to the other PBL schemes. The MYNN option in WRF is perhaps the PBL scheme that has experienced the most significant development since its original implementation in the code, mainly driven by developments targeting an improved skill of the WRF-based Rapid Refresh (RAP) and HighResolution Rapid Refresh (HRRR) operational products (Benjamin et al. 2016), as described in Olson et al. (2019a). A relevant component of the MYNN scheme that has evolved considerably over time is the formulation of the mixing length $\ell$. In our control MYNN simulations, we used the latest revision of the mixing length in the MYNN scheme (bl_mynn_mixlength=2), which is the one in use by the HRRR model since July 2018 and the default option in WRF version 4.0.1. To investigate the influence of the MYNN mixing-length formulation on the onset and development of the gravity waves, we carried out four additional experiments in which we configured the MYNN scheme to use the original mixing-length formulation by Nakanishi and Niino (2004) (MYNN0, bl_mynn_mixlength=0) and the first major revision of the mixing length employed by the HRRR from June 2016 to July 2018 (MYNN1, bl_mynn_mixlength=1). In addition, we performed the corresponding experiments employing MYNN in the parent domain and changed to these two options in the nested $1 \mathrm{~km}$ domain (S1-MYNN0 and S1-MYNN1).

Horizontal cross sections of vertical velocity for the additional sensitivity experiments to MYNN's mixing-length formulation are shown in Figs. $8 \mathrm{a}-\mathrm{d}$. These results indicate that the particular choice of mixing-length formulation among WRF's MYNN options does not produce any noticeable differences in terms of wave development, with the four additional MYNN simulations remaining consistent with our control MYNN experiments (other times and heights, not shown, display similar characteristics). In particular, the MYNN0 experiments resulted in the most significant suppression of wave activity and a stronger background stability, with no regions of Richardson number near its critical threshold within the $z=7.5-11.5 \mathrm{~km}$ MSL layer. Another recent extension of the MYNN scheme available in WRF is its blending with the eddy-diffusivity mass-flux (EDMF) scheme (bl_mynn_edmf =1), adapted from Angevine et al. (2010). Two additional tests were conducted to assess the impact of the EDMF nonlocal turbulent transport (MYNN-EDMF, 

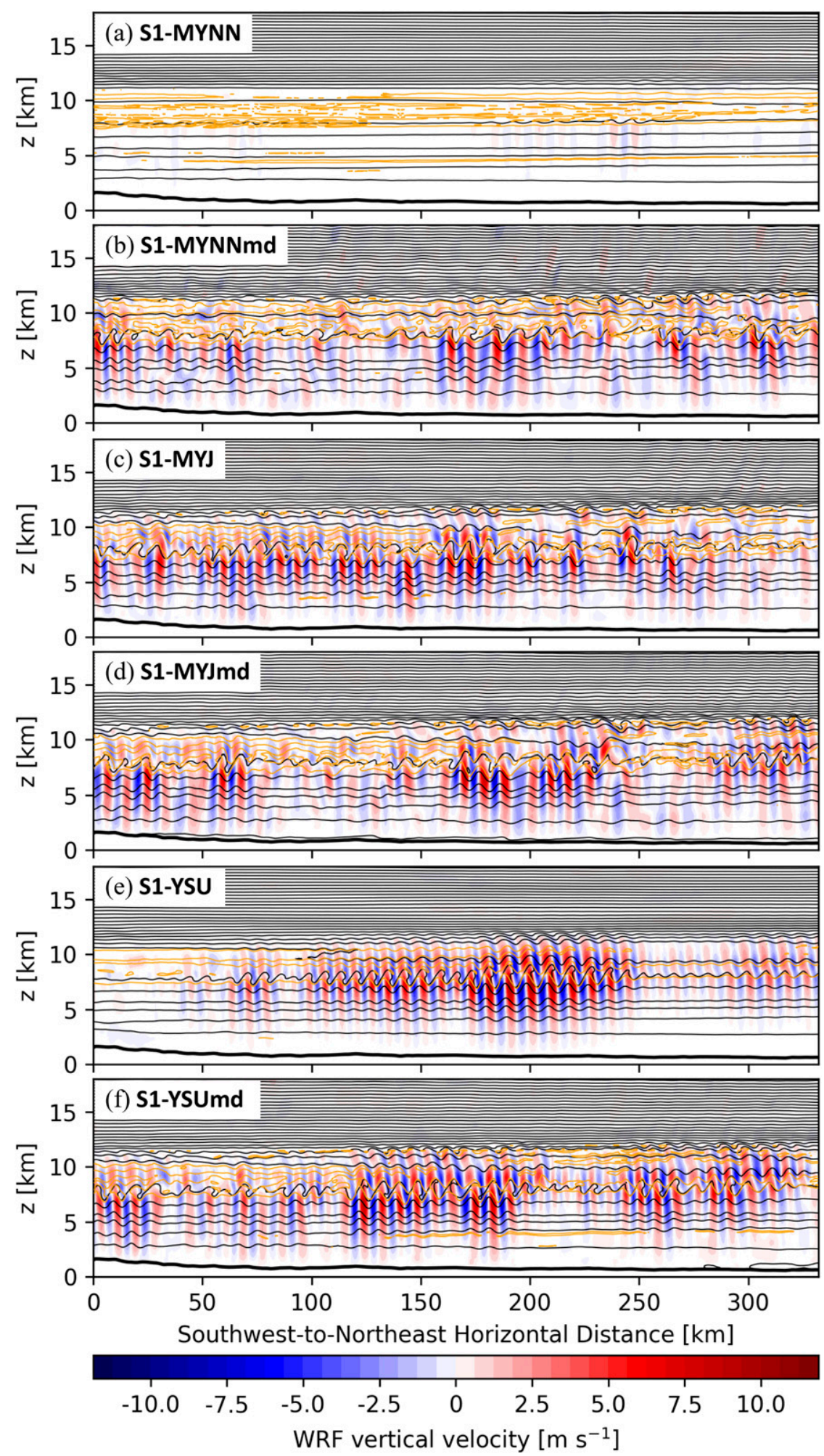

FIG. 6. Vertical cross sections along the SW-NE transect for the (a) S1-MYNN, (b) S1MYNNmd, (c) S1-MYJ, (d) S1-MYJmd, (e) S1-YSU, and (f) S1-YSUmd simulations on domain D02 $(\Delta x=1.0 \mathrm{~km})$ at 1600 UTC. Contours correspond to vertical velocity, black lines are isentropes plotted every $5 \mathrm{~K}$, and the yellow isolines correspond to a Richardson number of $\mathrm{Ri}=0.25$. 


\section{S1-MYNN (REF)}

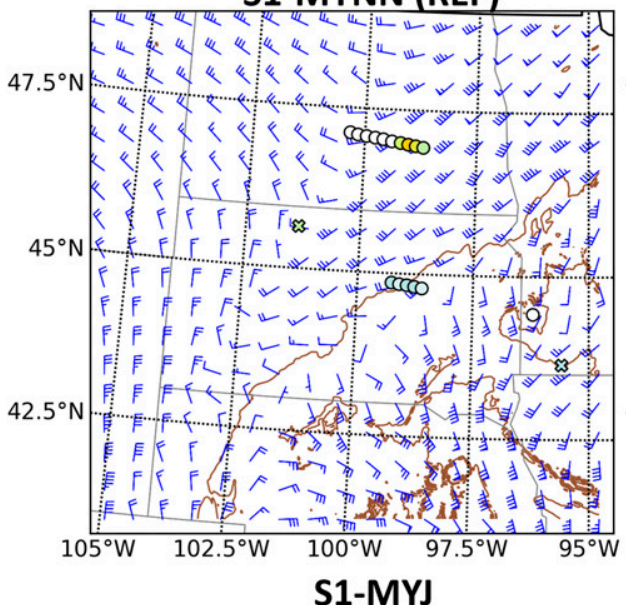

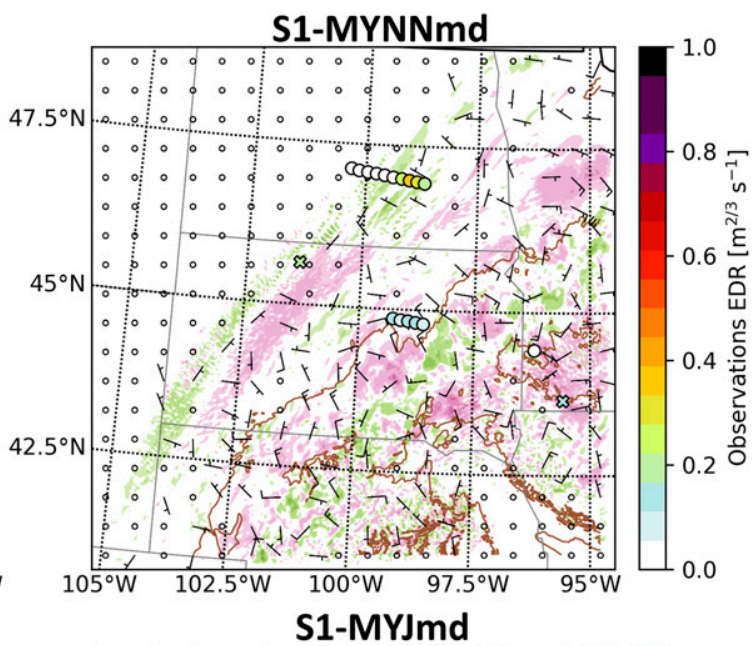

S1-MYNNmd

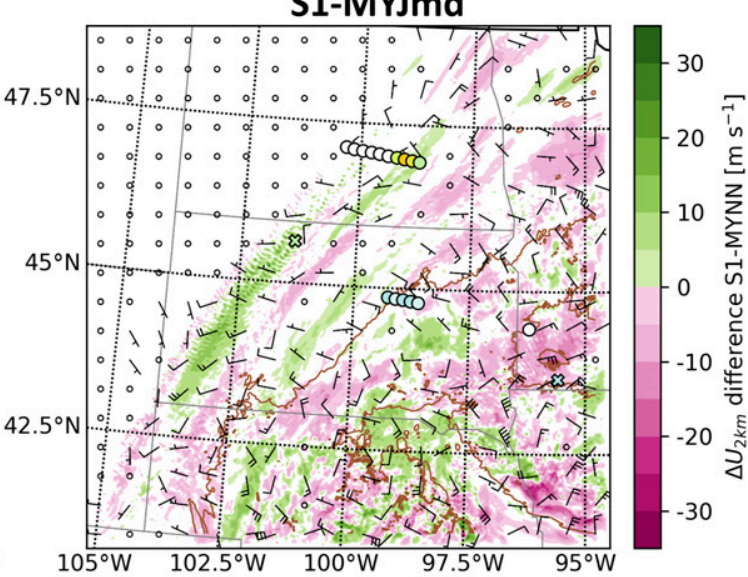

S1-YSUmd
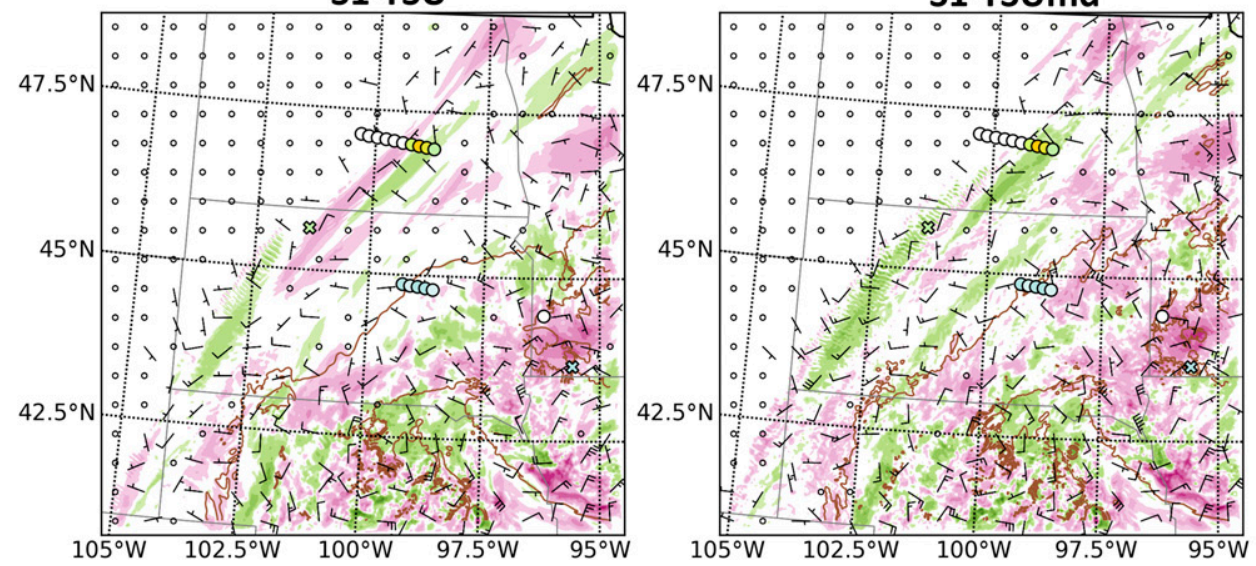

FIG. 7. Horizontal cross sections displaying contours of model vertical wind shear differences over the $6.0-8.0 \mathrm{~km}$ MSL layer, $\Delta U_{2 \mathrm{~km}}$, and differences in local wind magnitude and direction in the form of wind barbs at 1600 UTC $(z=7.0 \mathrm{~km} \mathrm{MSL})$. Differences are calculated with respect to the reference S1-MYNN simulation on domain D02 $(\Delta x=1.0 \mathrm{~km})$. Cloud boundary corresponding to a total cloud condensate threshold (brown line) of $q_{t}=0.005 \mathrm{~g} \mathrm{~kg}^{-1}$ (including water vapor, rain, snow, graupel, and ice hydrometeors) is displayed with a brown line. Turbulence observations within a $\pm 30 \mathrm{~min}$ time interval and $\pm 1000 \mathrm{ft}(\sim 300 \mathrm{~m})$ in height are included for reference, with circles denoting in situ EDR and crosses denoting PIREPs. 
(a) MYNNO

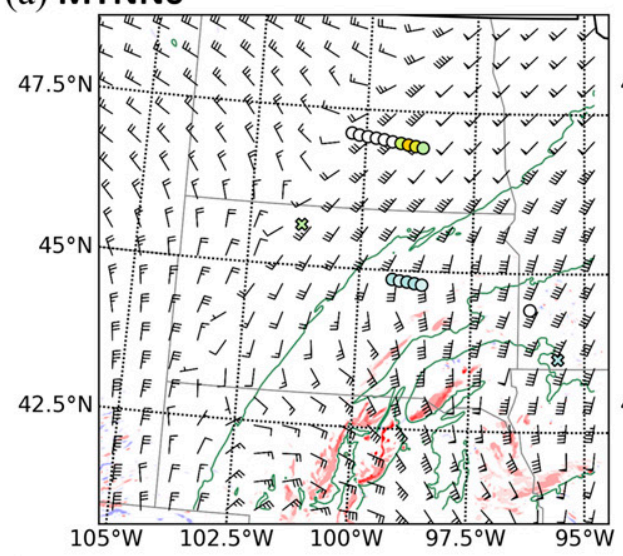

(c) MYNN1

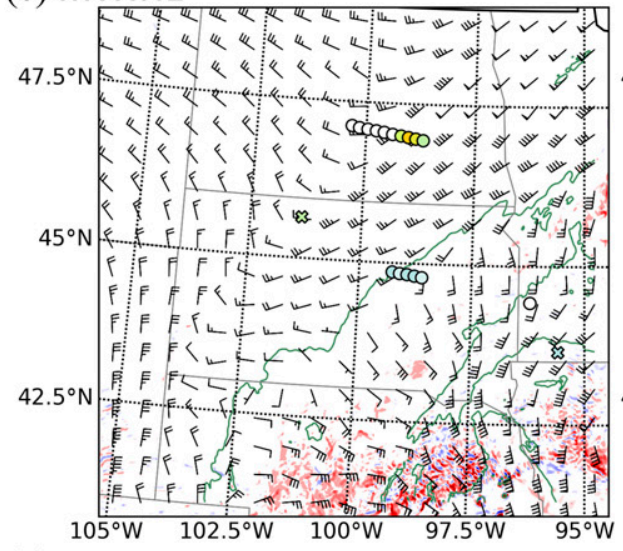

(e) MYNN-EDMF

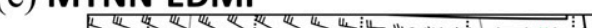

(b) S1-MYNNO

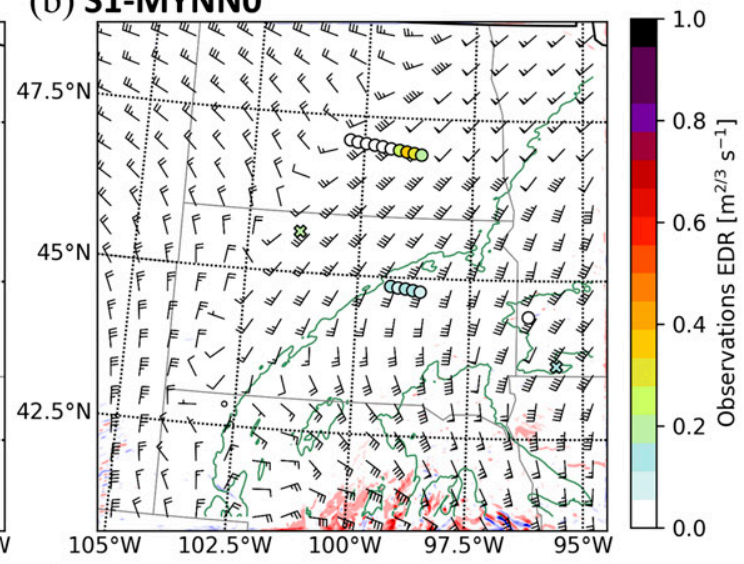

(d) S1-MYNN1

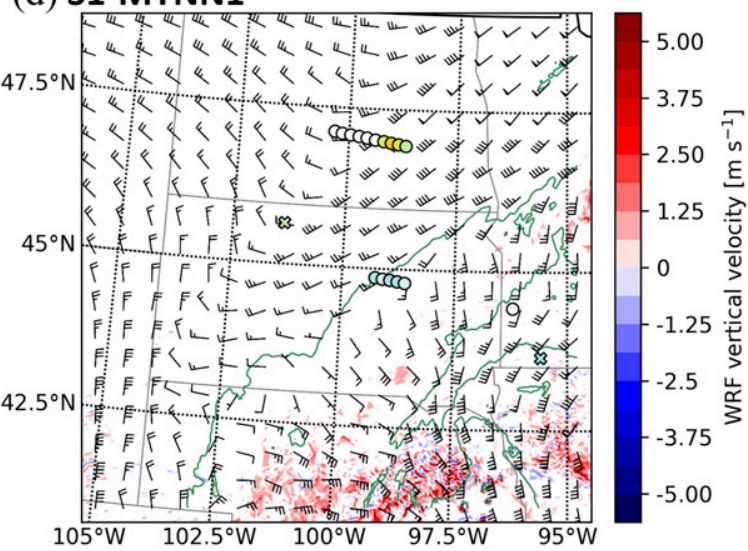

(f) S1-MYNN-EDMF

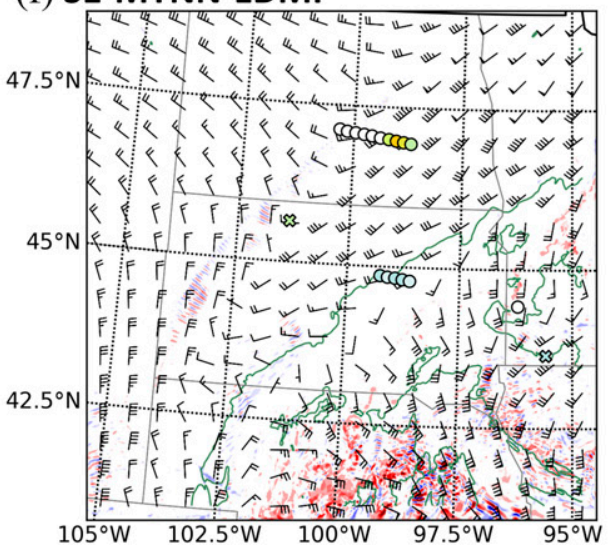

FIG. 8. Horizontal cross sections of model vertical velocity contours, wind barbs, and cloud boundary corresponding to a total cloud condensate threshold (green line) of $q_{t}=0.005 \mathrm{~g} \mathrm{~kg}^{-1}$ (including water vapor, rain, snow, graupel, and ice hydrometeors). Cross sections are taken at $z=7.0 \mathrm{~km}$ MSL for the sensitivity experiments with the MYNN scheme for simulation results on domain D02 $(\Delta x=1.0 \mathrm{~km})$ at 1600 UTC. The "S1" simulations all use the standard MYNN scheme on the parent domain $(\Delta x=3.0 \mathrm{~km})$. Turbulence observations within a \pm 30 min time interval and $\pm 1000 \mathrm{ft}(\sim 300 \mathrm{~m})$ in height are included for reference, with circles denoting in situ EDR and crosses denoting PIREPs.

S1-MYNN-EDMF), with the corresponding 1600 UTC contours of vertical velocity, cloud boundary, and wind barbs at $z=7.0 \mathrm{~km}$ MSL presented in Figs. 8e and 8f. The MYNNEDMF results exhibit incipient waves of similar amplitude to those in MYNN and S1-MYNN, and that are consistently weaker in amplitude and extent compared to the other PBL schemes and modified diffusion experiments. These tests point to the more dissipative nature of the MYNN scheme as a 
feature inherent to the basic formulation of the scheme (and/or its specific implementation in the WRF Model).

\section{Statistical comparison to a high-resolution large-eddy simulation}

Up to now, we have shown how SGS diffusion plays a critical role in UTLS wave and turbulence development, and that there are dramatic differences depending upon the particular PBL scheme formulation applied. However, while available aircraft turbulence observations are a key source of information to characterize approximate location, persistence and intensity of turbulence episodes, these measurements are only available along flight paths and do not typically provide the required spatial coverage to properly assess the performance of $1 \mathrm{~km}$ NWP models in characterizing the environment and turbulence mechanisms of UTLS turbulence. To address this, we perform a higher-resolution nested WRF-LES to be used as reference, where the most energetic wave and turbulence motions are resolved and only smaller-scale isotropic eddies are parameterized. Due to the significant computational resources required, the LES technique used in previous UTLS simulation studies has been primarily restricted to simplified or even two-dimensional setups (e.g., Joseph et al. 2004; Mahalov et al. 2004; Lane and Knievel 2005; Paoli et al. 2014), integrated over a relatively short time period and for which idealized forcing conditions are applied (e.g., Zovko-Rajak and Lane 2014; Lane and Sharman 2014). As already discussed, we performed fine-resolution nested LES $(\Delta x=250 \mathrm{~m}, \Delta z=$ $100 \mathrm{~m}$ ) over a domain spanning $1000 \mathrm{~km} \times 1000 \mathrm{~km} \times 22.5 \mathrm{~km}$, leading to a total of 2.4 billion grid points integrated for a physical time of $12 \mathrm{~h}$ (0600-1800 UTC). This fine-grid-spacing real-case LES over such a large spatial extent is, to our knowledge, beyond any published computational work to date in this field. ${ }^{4}$

An important aspect to consider when comparing the $1 \mathrm{~km}$ mesoscale simulations to the reference LES, is the contribution from the smaller scales present in the latter. To warrant a fair comparison despite the differences in $\Delta x$, we filter all of the results in a consistent manner. Filtering is performed in Fourier space, employing a two-dimensional lowpass Butterworth filter (Butterworth 1930), $B(\kappa)=\left[1.0+\left(\kappa / \kappa_{c}\right)^{2 n}\right]^{-0.5}$, where $\kappa$ is the wavenumber, $\kappa_{c}$ is the cutoff wavenumber, and $n$ is the order of the filter. Given the effective resolution of WRF in our simulations, we set $\kappa_{c}^{-1}=6000 \mathrm{~m}$ (corresponding to $6 \Delta x$ in the $1 \mathrm{~km}$ simulations). As for the filter order, we use $n=12$. We find the twelfth-order lowpass Butterworth filter to be a good compromise between a too-sharp top-hat filter, $n \rightarrow \infty$, which tends to induce gridscale noise (Gibbs phenomena) and a low-order filter that would not be sufficiently scale selective. This approach is more accurate than the simple patch averaging often employed when coarse-graining LES results (e.g., Honnert et al. 2011; Shin and Hong 2013; Zhou et al. 2014). In addition, model fields are smoothed using a halved Hamming window over the nearest $25.0 \mathrm{~km}$ to the domain lateral boundaries in

\footnotetext{
${ }^{4}$ This computationally intensive nested WRF-LES was run on NCAR's supercomputer Cheyenne over 9000 parallel CPU cores.
}
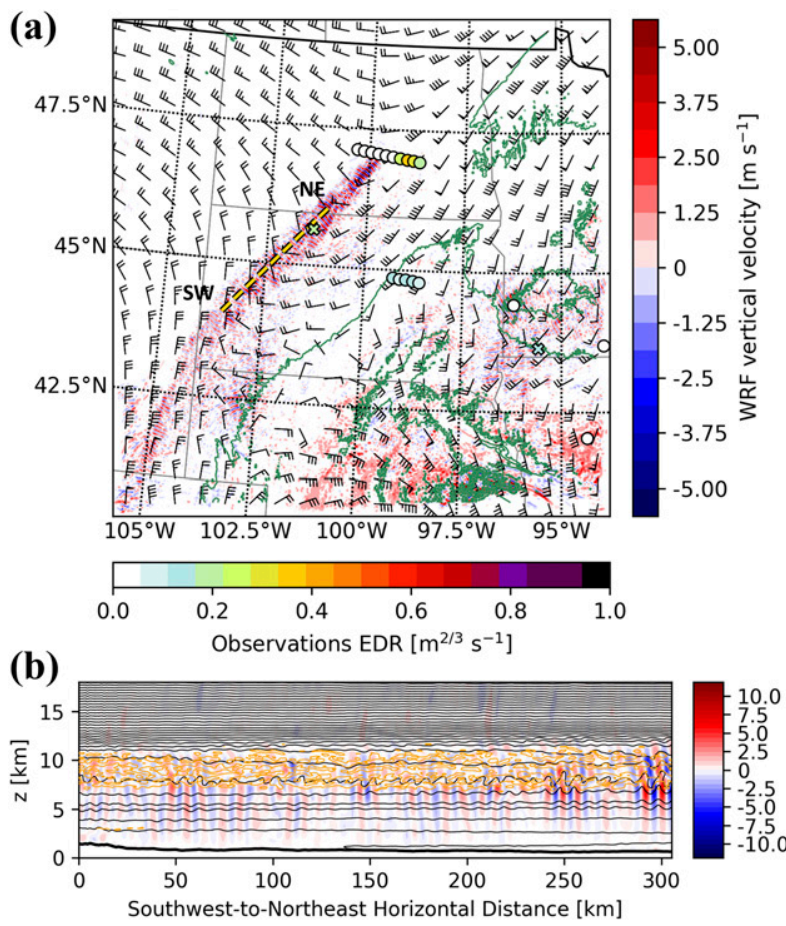

FIG. 9. Cross sections from the filtered LES model results at 1600 UTC. (a) Horizontal cross section of model vertical velocity contours, wind barbs, and cloud boundary corresponding to a total cloud condensate threshold (green line) of $q_{t}=0.005 \mathrm{~g} \mathrm{~kg}^{-1}$ (including water vapor, rain, snow, graupel, and ice hydrometeors) at $z=7.0 \mathrm{~km}$ MSL. The dashed SW-NE line indicates the transect for the vertical cross section in (b). Turbulence observations within a $\pm 30 \mathrm{~min}$ time interval and $\pm 1000 \mathrm{ft}(\sim 300 \mathrm{~m})$ in height are included for reference, with circles denoting in situ EDR and crosses denoting PIREPs. (b) Vertical cross sections along the SW-NE transect in (a) including vertical velocity (contours), isentropes plotted every $5 \mathrm{~K}$ (black lines), and isolines of $\mathrm{Ri}=0.25$ (yellow lines).

physical space, in order to prevent the presence of discontinuities when performing the FFT calculations.

Figure 9 shows an example of the filtered WRF-LES results at 1600 UTC. The gravity waves present at $z=7.0 \mathrm{~km} \mathrm{MSL} \mathrm{in}$ the LES results are consistently to the northwest of the cloud boundary, although they are situated at a slightly different location than in the $1 \mathrm{~km}$ runs, which we attribute to the finer grid resolution promoting local changes in the larger scales through upscale energy transfer (e.g., Sandery and Sakov 2017) and to the imperfections of SGS parameterizations. Nevertheless, a similar gravity wave pattern to the one found in the majority of the $1 \mathrm{~km}$ mesoscale simulations is observed. The $w$ contours along the SW-NE transect indicate similar vertical structure of the atmosphere to the $1 \mathrm{~km}$ simulations, including the location of gravity waves beneath a layer of $\mathrm{Ri}<0.25$. However, the amplitudes of the waves at that particular time are reduced in the LES compared to the $1 \mathrm{~km}$ cases.

Given the predictability issues associated with the spatiotemporal onset of the wave and turbulence instabilities we are analyzing, further amplified by the difference in grid resolutions, it is not possible to compare specific events at a particular time. 

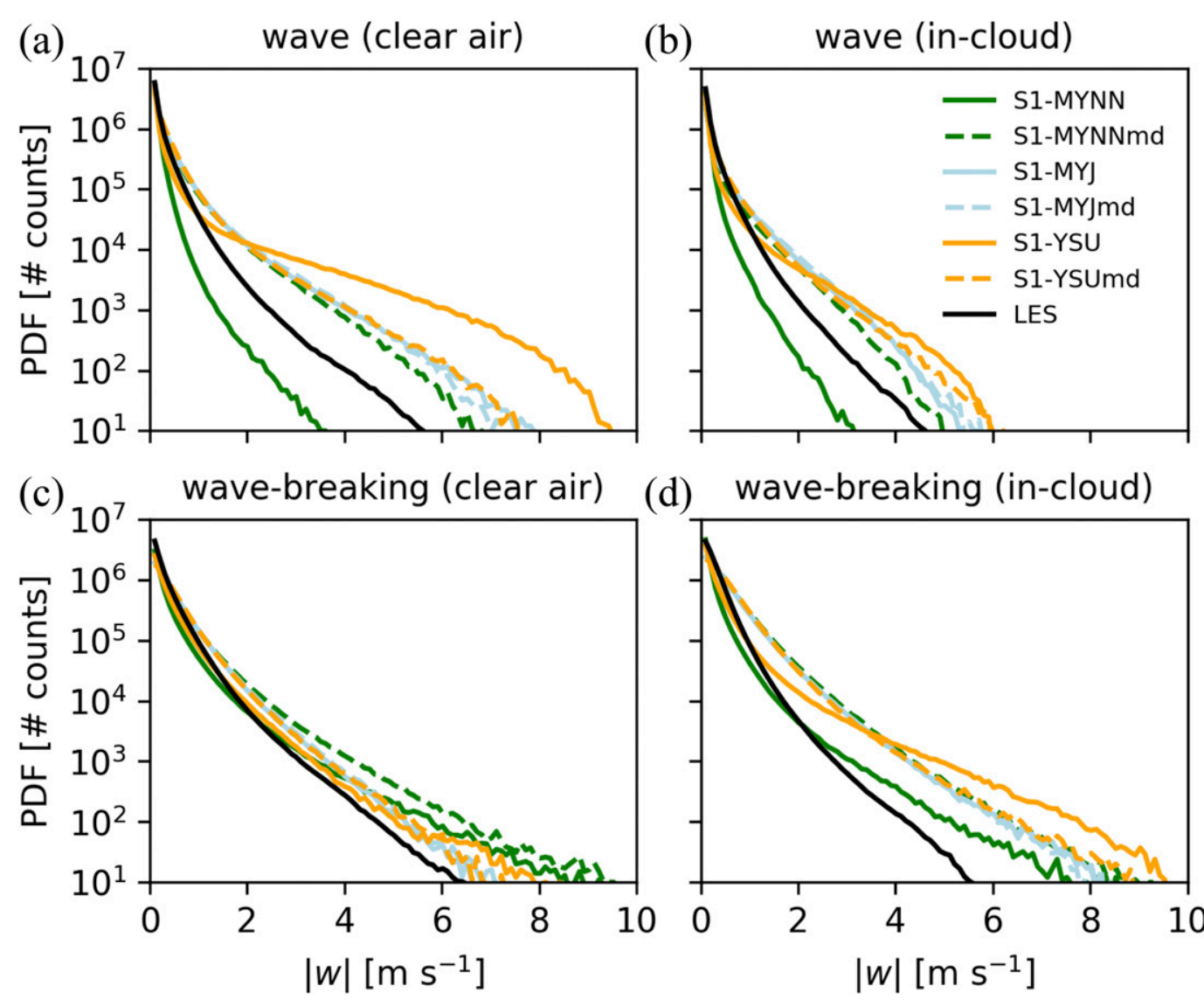

(d) wave-breaking (in-cloud)

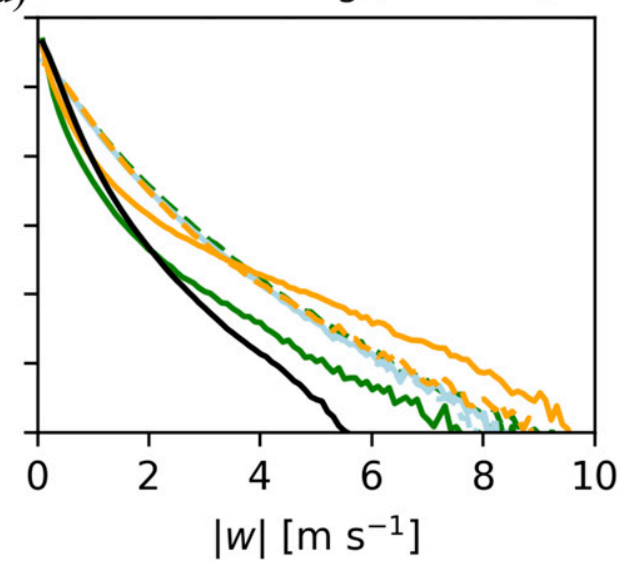

FIG. 10. Probability density functions (PDFs) of absolute value of vertical velocity $|w|$ corresponding to the (a),(b) "wave" (5.0 $\leq z \leq 7.5 \mathrm{~km} \mathrm{MSL)}$ and (c),(d) "wave-breaking" ( $8.0 \leq z \leq 10.5 \mathrm{~km}$ MSL) regions for (a),(c) "clear air" $\left(q_{\mathrm{tot}}<10^{-7} \mathrm{~g} \mathrm{~kg}^{-1}\right)$ and (b), (d) "in-cloud" or convectively influenced $\left(q_{\mathrm{tot}} \geq 10^{-7}\right)$ conditions within the 1500-1730 UTC time window. S1 simulations and reference LES are lowpass filtered employing a twelfth-order Butterworth filter with $\kappa_{c}^{-1}=6000 \mathrm{~m}$.

Instead, one can evaluate the probabilistic behavior of relevant quantities. To that end, we compute probability density functions (PDFs) of absolute vertical velocity, presented in Fig. 10. Given some previously noted differences in the nature of the wave and turbulence mechanisms in the different locations of the domain, as discussed in Trier et al. (2020), we split the domain into four regions. Two vertical ranges are considered based upon the clear-air dynamics: the "wave" region where the trapped internal gravity waves are present $(5.0 \leq z \leq 7.5 \mathrm{~km}$ MSL) and the "wave-breaking" region where KHI leads to turbulence ( $8.0 \leq z \leq 10.5 \mathrm{~km} \mathrm{MSL})$. Additional separation is provided between "clear air," $q_{\text {tot }}<10^{-7} \mathrm{~g} \mathrm{~kg}^{-1}$, and "in-cloud" or convectively influenced, $q_{\text {tot }} \geq 10^{-7} \mathrm{~g} \mathrm{~kg}^{-1}$, regions, and over the 1500-1730 UTC time window where wave and turbulence activity was more pronounced.

Probability density functions for the wave clear-air region (Fig. 10a) confirm that all of the 1-km simulations with clearly discernible waves (with the exception of S1-MYNN) exhibit distributions having larger $w$ amplitudes compared to the reference filtered LES. Not surprisingly, the modified diffusion schemes result in a reasonable convergence, and the YSU scheme leads to the largest overestimates of $w$ consistent with the strong and coherent waves seen in Fig. 5e. In contrast, the MYNN scheme underpredicts wave activity and the MYNN simulation possesses the weakest $w$ values compared to the LES distribution. These findings are overall valid for the four regions, with some peculiarities worth emphasizing. Within the two wave-breaking regions (Figs. 10c,d), all of the $1 \mathrm{~km}$ simulations produce vertical motions typically larger than the LES, suggesting that smaller-scale turbulence and moist processes may affect the balance provided by the SGS parameterizations in slightly different manners. Moreover, S1-MYJ and S1MYJmd simulations result in nearly identical distributions, attributed to MYJ's master length-scale definition and stability functions likely leading to a significant suppression of SGS TKE outside the ABL, and therefore minimal addition of explicit SGS diffusion within the UTLS.

Probability distributions of resolved momentum flux, $\left\langle w^{\prime} u^{\prime}\right\rangle$, heat flux, $\left\langle w^{\prime} \theta^{\prime}\right\rangle$, and wave kinetic energy, WKE $=$ $0.5\left\langle u^{\prime 2}+v^{\prime 2}+w^{2}\right\rangle$, are presented in Fig. 11 for the wave clearair region. A moving $20 \mathrm{~km} \times 20 \mathrm{~km}$ horizontal square region is considered to calculate perturbation quantities at the wave scale, indicated by primes, and where the angle brackets denote averaging over time and a spatial region. Wave-scale 

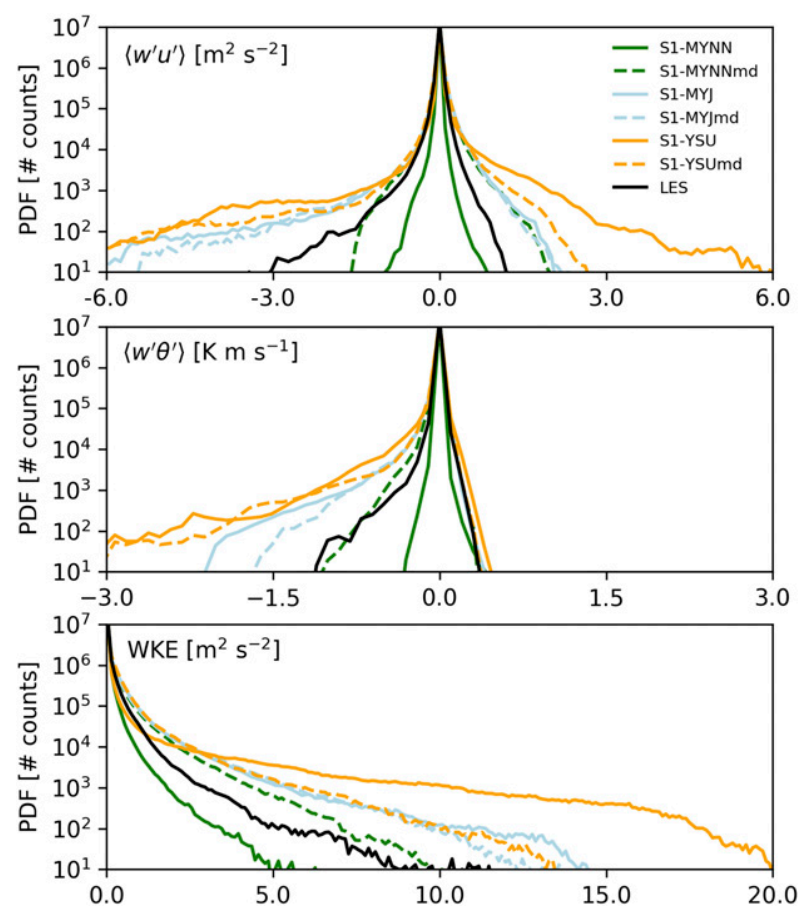

FIG. 11. Probability density functions (PDFs) of (top) wave-scale momentum flux, $\left\langle w^{\prime} u^{\prime}\right\rangle$, (middle) heat flux, $\left\langle w^{\prime} \theta^{\prime}\right\rangle$, and (bottom) kinetic energy, WKE, corresponding to the wave clear-air region $\left(5.0 \leq z \leq 7.5 \mathrm{~km} \mathrm{MSL}, q_{\text {tot }}<10^{-7} \mathrm{~g} \mathrm{~kg}^{-1} \mathrm{MSL}\right)$ within the 1500 1730 UTC time window. Perturbation quantities are computed over a $20 \mathrm{~km} \times 20 \mathrm{~km}$ square box. S1 simulations and reference LES, are lowpass filtered employing a twelfth-order Butterworth filter with $\kappa_{c}^{-1}=6000 \mathrm{~m}$.

fluxes and kinetic energy display a similar pattern to the PDFs of $|w|$, however, with a larger spread within probability distributions for the modified diffusion simulations. In particular, momentum flux is doubled by all of the PBL schemes for the large-amplitude low probability events pertaining to the most energetic wave-induced contributions, with a significant departure by S1-YSU from the LES distribution for positive $\left\langle w^{\prime} u^{\prime}\right\rangle$. This reveals an incorrect effect introduced by the SGS diffusion into the resolved flow field, which leads to a systematic and unrealistic appearance of strong outward interactions (i.e., $\left\langle w^{\prime} u^{\prime}\right\rangle>0$ ). Heat flux PDFs are more consistent, with all of the schemes presenting an excellent agreement in reproducing the positive $\left\langle w^{\prime} \theta^{\prime}\right\rangle$ instances, despite the overprediction of cooling wave-scale flux magnitudes. The WKE distributions reveal a similar signature to that found with the absolute vertical velocity PDFs, indicating a dominant role of vertical motions in the total wave kinetic energy budget.

A more detailed perspective into the energy partitioning across scales can be gained by examining the energy spectra presented in Fig. 12. These two-dimensional spectra are calculated for the $w$ field interpolated at constant altitude surfaces, and azimuthally grouped over constant wavenumber rings, calculating median (P50) and 90th-percentile (P90) values. Vertical velocity is masked out using total cloud content to discriminate between clear-air and in-cloud (or convectively influenced) conditions, as well as to separate wave and wavebreaking regions in the vertical direction, in the same manner to that used for the PDFs. The median $w$ spectra within the wave region in clear air (Fig. 12a) shows a trend of vertical variance decreasing from the large scales up to wavelengths of $\lambda \approx$ $100 \mathrm{~km}$, after which energy commences to increase toward smaller scales. A clear peak for $\lambda \approx 10 \mathrm{~km}$ is displayed, corresponding to the presence of gravity waves in this region. The skill of the different PBL schemes in capturing the amplitude and length scale of the dominant wave structures is quantified by computing the ratio of the maximum vertical velocity energy spectra, $E_{\mathrm{pr}}=E_{w_{\max }, \mathrm{PBL}} / E_{w_{\max }, \mathrm{LES}}$, and the corresponding wavelength ratio, $\lambda_{\mathrm{pr}}=\lambda_{\mathrm{PBL}} / \lambda_{\mathrm{LES}}$. All of the modified diffusion simulations, as well as S1-MYJ, share similar characteristics, with energy levels exceeding the LES energy content at the wave peak by $E_{\mathrm{pr}} \approx 2.5$, and shifted toward larger wavelengths, $\lambda \approx 8.5 \mathrm{~km}$, with a ratio of peak wavelength to the LES of $\lambda_{\mathrm{pr}} \approx 1.2$.

The simulation employing the standard YSU scheme (i.e., without removing diffusion for $z>1.2 z_{i}$ ) shows considerably smaller differences with respect to the filtered LES, resulting in a reduced overestimation of the peak energy, $E_{\mathrm{pr}} \approx 1.2$, although still overpredicting the peak wavelength similarly to the other simulations. Consistent behavior is found at the wavebreaking region, both for clear-air and in-cloud conditions, as shown in Figs. 12c and 12d. Examination of the corresponding 90th-percentile spectra (Fig. 12b) reveals a dramatic energy overestimation by S1-YSU, with $E_{\mathrm{pr}} \approx 10.0$. This is in fact evidence of a degraded performance, since these waves or turbulence activity are more of a localized episode, implying a considerable overforecasting of wave activity and its strength by the YSU scheme. In contrast, the S1-MYNN simulation is consistently overdiffusive in all regions/conditions, while the corresponding modified diffusion simulation does systematically overpredict vertical velocity variance (S1-MYNNmd). Comparison of these two indicates the tremendous impact of the vertical SGS mixing arising from the PBL scheme in these fine-resolution $1 \mathrm{~km}$ mesoscale simulations.

The peak wavenumber in the LES, $\lambda \approx 7.0 \mathrm{~km}$, is close to the effective resolution in the $1 \mathrm{~km}$ simulations. At these resolutions, the smallest scales resolvable by the model are where the most energetic wave activity occurs, further complicating the parameterization of SGS effects and pointing to a gray-zone type of modeling issue (e.g., Wyngaard 2004; Chow et al. 2019). While the development of scale-aware parameterizations for atmospheric boundary layer turbulence and shallow cumulus clouds has gained significant popularity over the past several years (e.g., Shin and Hong 2015; Sakradzija et al. 2016; Zhang et al. 2018; Wagner et al. 2018), we are not aware of similar efforts in the context of UTLS wave dynamics, which are likely to require specifically designed parameterizations.

At this point, it is worth emphasizing that WRF mesoscale simulations typically include the so-called 2D Smagorinsky diffusion along model coordinate surfaces (Smagorinsky 1963), commonly regarded by the modeling community as a SGS model for 2D turbulence. However, this is in fact a secondorder spatial filter where the eddy diffusivities are formulated based on horizontal shear components, employed to stabilize computations using the nonlinear eddy viscosity concept 

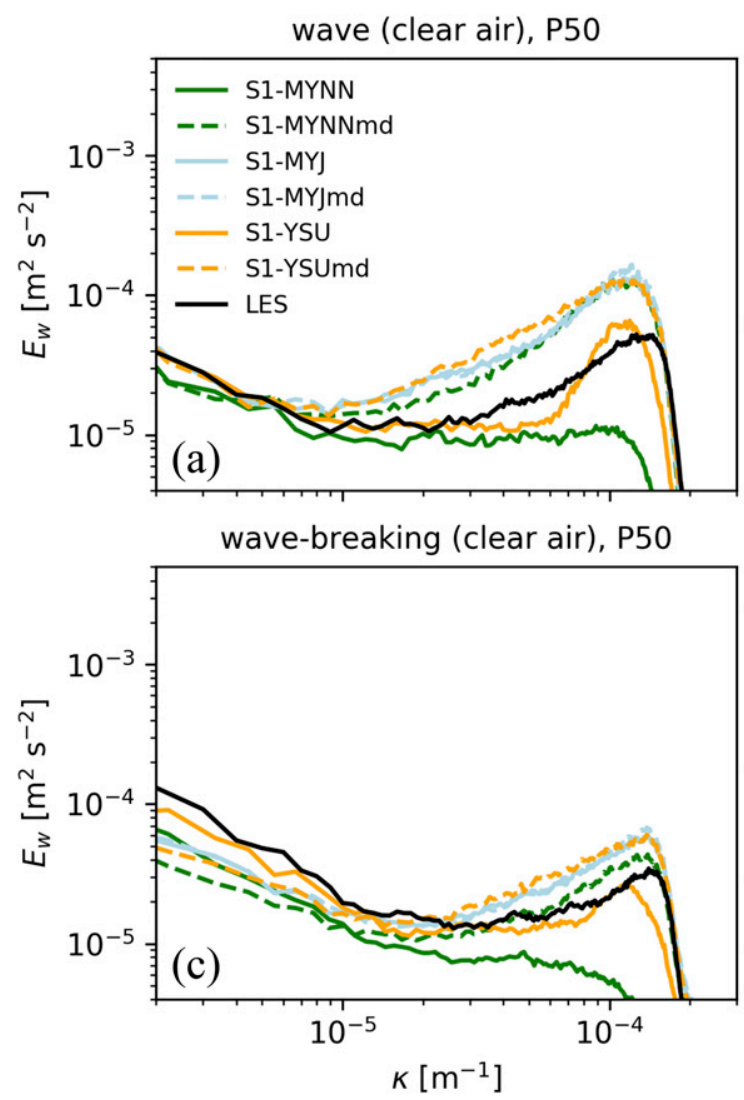
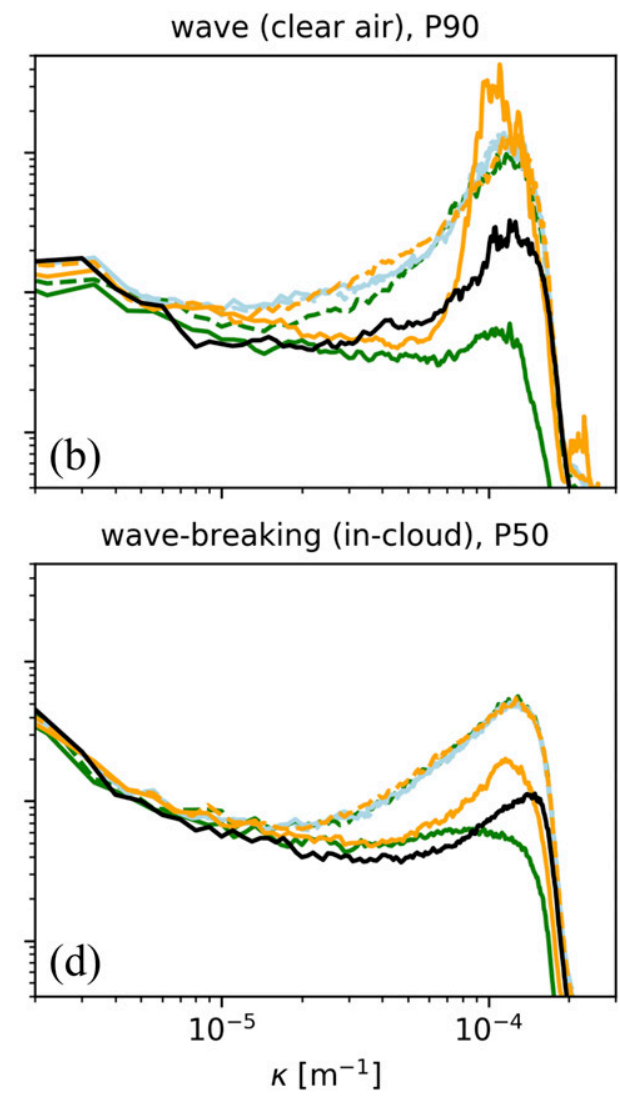

FIG. 12. Energy spectra of vertical velocity $E_{w}$. One-dimensional spectra are derived from percentiles over azimuthal rings of constant wavenumber, $\kappa=\sqrt{\kappa_{x}^{2}+\kappa_{y}^{2}}$, for the 50th (P50, median) and the 90th percentiles (P90) computed from two-dimensional spectra. S1 simulations and reference LES are all low-pass filtered employing a twelfth-order Butterworth filter with $\kappa_{c}^{-1}=6000 \mathrm{~m}$.

(Von Neumann and Richtmyer 1950; Smagorinsky 1993). This additional source of horizontal mixing can be interpreted as SGS diffusion for heat and other scalars, but it lacks the cross-terms required for a full SGS model for momentum. Horizontal 2D Smagorinsky mixing is found to be less dominant than the vertical counterpart in our cases, but nevertheless needs to be revisited for fine-resolution mesoscale NWP simulations in which small-scale wave activity starts to be partly resolved.

\section{Conclusions}

The role of PBL scheme diffusion on the UTLS resolved wave and turbulence characteristics as represented in high-resolution WRF v4.0.1 simulations has been thoroughly examined. To investigate this aspect, we perform a series of one-way nested simulations of $\Delta x=1.0 \mathrm{~km}$ (inner domain) in which we vary the PBL scheme treatment, for a real case corresponding to a UTLS widespread turbulence event related to the passage of a strong midlatitude cyclone on 30 April 2017 over the contiguous United States. In one set of simulations we employ the same PBL scheme in both domains (MYNN, MYJ, and YSU), which is the standard method of executing WRF. For each of these simulations, good agreement was obtained with observed large-scale radar reflectivities in the coarser $\Delta x=3 \mathrm{~km}$ parent domain and more locally with observed vertical sounding profiles on the $1 \mathrm{~km}$ one-way interactive nest. When examining the $1 \mathrm{~km}$ domain fields, a remarkable sensitivity in the development of short-wavelength gravity waves beneath the convectively enhanced UTLS outflow jet was found among different simulations, linked to the PBL scheme formulation, with the MYNN and YSU schemes not exhibiting noticeable wave activity, in significant contrast to the MYJ simulation.

In a second experiment, designed to reduce the effect of the large-scale forcing arising from the lateral boundary conditions on the nested domain, only MYNN was used on the parent domains. This experiment revealed that the coarser-resolution domain, where waves are not resolved, has an indirect impact on the background forcing conditions through modification of wind shear and potential temperature gradient profiles, required for the waves to develop and propagate. Unlike in the previous experiment, the simulation using the YSU scheme in the inner nest (and MYNN in the parent domain) resulted in the formation of gravity waves. We tested an ad hoc modification in which PBL scheme diffusion is removed for $z>1.2 z_{i}$. We find that all the simulations with modified diffusion are able 
to consistently generate gravity waves, and that PBL scheme diffusion can locally suppress shear, in turn preventing the onset of KHI. Also, it is found that PBL scheme diffusion plays no role over quiescent regions in clear-air conditions where there is no small-scale activity, while this is not the case in-cloud or in convectively influenced regions located outside of cloud.

The accuracy of the different PBL schemes in the UTLS is assessed in a statistical sense utilizing higher-resolution LES as reference $(\Delta x=250 \mathrm{~m})$. All of the $1 \mathrm{~km}$ simulations that display these gravity waves result in higher probabilities of larger vertical velocity values, particularly exceeding the reference LES in the case of the YSU scheme, and with the modified diffusion experiments depicting a consistent behavior at different regions both for in-cloud and clear-air conditions. Similar characteristics are observed for wave-scale momentum and heat fluxes, as well as for kinetic energy. Analysis of $w$ spectra reveals a consistent energy overprediction at wave peak scales of $E_{\mathrm{pr}} \approx 2.5$, when considering median energy content along constant two-dimensional wavenumber rings, and with the peak occurring at larger wavelengths in the $1 \mathrm{~km}$ simulations $\left(\lambda_{\mathrm{pr}} \approx 1.2\right)$. Despite the YSU scheme resulting in a closer agreement with the reference LES, 90th-percentile energy content reveals an order of magnitude overprediction, indicative of inappropriate SGS diffusion. While the modified diffusion approach led to a consistent behavior in all cases, we expect such an implicit SGS turbulence treatment not to be appropriate at these type of resolutions, where the effective resolution lies in the region where wave-energy production is more predominant, thus requiring a scale-aware gray-zone type of parameterization tailored to provide the appropriate closure for partially resolved wave dynamics. In addition, sensitivity experiments to the mixing length formulation option and the incorporation of a nonlocal EDMF component to the MYNN scheme revealed a consistent overly diffusive behavior regarding the representation of these small-scale gravity waves.

High-resolution mesoscale NWP model simulations provide a way for researchers to gain insight into small-scale wave and turbulence activity, which has become a standard for the aviation turbulence research community over the last decade. While we have focused on the WRF Model for our numerical experiments, similar types of 1D PBL schemes are the standard approach in global and regional NWP models as well, and therefore we anticipate our results are of general relevance and applicability to the NWP modeling community at large. Some examples of other NWP models using similar first-order $K$-profile approaches include the Korean Integrated Model (KIM; Hong et al. 2018, which employs the YSU scheme), the Met Office Unified Model (UM; Walters et al. 2019), the European Centre for Medium-Range Weather Forecasts model (ECMWF; Köhler et al. 2011), and the National Centers for Environmental Prediction's Global Forecast System model (GFS; Han and Pan 2011), while the Coupled Ocean-Atmosphere Mesoscale Prediction System (COAMPS; Hodur 1997) and the Consortium for Small-Scale Modeling (COSMO; Doms and Schättler 1999) models apply 1.5-order TKE-based PBL schemes, to name a few relevant and often used NWP models worldwide. Herein, we have demonstrated the dramatic impact of PBL scheme diffusion in mesoscale simulations where gravity waves are partly resolved. Given this strong dependency of the simulated results, we recommend practitioners to at least perform some sensitivity analysis to the PBL scheme option when a possibility in their models. For the cases where such PBL sensitivity analysis cannot be afforded, we recommend using the MYJ scheme, which as demonstrated from our analysis, will likely allow the onset and propagation of gravity waves and turbulence instabilities, even if systematically overpredicting the strength of these features. The current lack of agreement among PBL scheme treatment points to the need for ensembles that include varied PBL scheme options as different members, before a more unified scale-aware UTLS SGS wave/turbulence scheme is available for these fine grid resolutions.

The use of PBL SGS parameterization schemes tends to overestimate the strength of wave activity for UTLS simulations according to our numerical experiments, with the exception of the MYNN scheme that appears to have a more dissipative nature at these fine resolutions. This is a relevant aspect for practical applications given the popularity of the MYNN scheme within the NWP modeling community, employed among others by the WRF-based High-Resolution Rapid Refresh (HRRR) operational product (Smith et al. 2008). The HRRR model currently uses $\Delta x=3.0 \mathrm{~km}$, but it is expected to reach higher resolutions in the near future, and that could lead to a consistent underprediction of UTLS wave activity and strength. In fact, there have been prototype experiments pushing to subkilometer resolutions, $\Delta x=750 \mathrm{~m}$, targeting an improved modeling of the wind field within the atmospheric boundary layer for wind energy purposes (Olson et al. 2019b). We encourage this type of efforts to also consider the impact of PBL scheme diffusion on UTLS flows, in particular regarding the representation of wave and turbulence activity.

Acknowledgments. This research is in response in part to requirements and funding by the Federal Aviation Administration (FAA). The views expressed are those of the authors and do not necessarily represent the official policy or position of the FAA. All the simulations were performed using high-performance computing support from Cheyenne (https://doi.org/10.5065/ D6RX99HX) provided by NCAR's Computational and Information Systems Laboratory, sponsored by the National Science Foundation. The specific computing time was provided by the NCAR Strategic Capability Computing Grant "Large-eddy simulations of a clear-air upper-level turbulence event with the Weather Research and Forecasting model" (NRAL0021). All simulations reported in this study are available from the corresponding author upon request.

\section{REFERENCES}

Angevine, W. M., H. Jiang, and T. Mauritsen, 2010: Performance of an eddy diffusivity-mass flux scheme for shallow cumulus boundary layers. Mon. Wea. Rev., 138, 2895-2912, https:// doi.org/10.1175/2010MWR3142.1.

Barber, K. A., G. L. Mullendore, and M. J. Alexander, 2018: Out-ofcloud convective turbulence: Estimation method and impacts of model resolution. J. Appl. Meteor. Climatol., 57, 121-136, https:// doi.org/10.1175/JAMC-D-17-0174.1. 
Benjamin, S. G., and Coauthors, 2016: A North American hourly assimilation and model forecast cycle: The Rapid Refresh. Mon. Wea. Rev., 144, 1669-1694, https://doi.org/ 10.1175/MWR-D-15-0242.1.

Blackadar, A. K., 1962: The vertical distribution of wind and turbulent exchange in a neutral atmosphere. J. Geophys. Res., 67, 3095-3102, https://doi.org/10.1029/JZ067i008p03095.

Butterworth, S., 1930: On the theory of filter amplifiers. Wireless Eng., 7, 536-541.

Chow, F. K., C. Schär, N. Ban, K. A. Lundquist, L. Schlemmer, and X. Shi, 2019: Crossing multiple gray zones in the transition from mesoscale to microscale simulation over complex terrain. Atmosphere, 10, 274, https://doi.org/10.3390/atmos10050274.

Deardorff, J. W., 1980: Stratocumulus-capped mixed layers derived from a three-dimensional model. Bound.-Layer Meteor., 18, 495-527, https://doi.org/10.1007/BF00119502.

Doms, G., and U. Schättler, 1999: The nonhydrostatic limited-area model LM (Lokal-Modell) of the DWD. Part I: Scientific documentation. Tech. Rep., German Weather Service (DWD), 174 pp.

Feltz, W., K. Bedka, J. Otkin, T. Greenwald, and S. Ackerman, 2009: Understanding satellite-observed mountain-wave signatures using high-resolution numerical model data. Wea. Forecasting, 24, 76-86, https://doi.org/10.1175/2008WAF2222127.1.

Garratt, J. R., 1994: The Atmospheric Boundary Layer. Cambridge University Press, 316 pp.

Han, J., and H.-L. Pan, 2011: Revision of convection and vertical diffusion schemes in the NCEP global forecast system. Wea. Forecasting, 26, 520-533, https://doi.org/10.1175/WAF-D-1005038.1.

Hodur, R. M., 1997: The Naval Research Laboratory's Coupled Ocean/Atmosphere Mesoscale Prediction System (COAMPS). Mon. Wea. Rev., 125, 1414-1430, https://doi.org/10.1175/15200493(1997)125<1414:TNRLSC > 2.0.CO;2.

Hong, S.-Y., Y. Noh, and J. Dudhia, 2006: A new vertical diffusion package with an explicit treatment of entrainment processes. Mon. Wea. Rev., 134, 2318-2341, https://doi.org/ 10.1175/MWR3199.1.

— , and Coauthors, 2018: The Korean Integrated Model (KIM) system for global weather forecasting. Asia-Pac. J. Atmos. Sci., 54, 267-292, https://doi.org/10.1007/s13143-018-0028-9.

Honnert, R., V. Masson, and F. Couvreux, 2011: A diagnostic for evaluating the representation of turbulence in atmospheric models at the kilometric scale. J. Atmos. Sci., 68, 3112-3131, https://doi.org/10.1175/JAS-D-11-061.1.

Iacono, M. J., J. S. Delamere, E. J. Mlawer, M. W. Shephard, S. A. Clough, and W. D. Collins, 2008: Radiative forcing by longlived greenhouse gases: Calculations with the AER radiative transfer models. J. Geophys. Res., 113, D13103, https://doi.org/ 10.1029/2008JD009944.

Janjić, Z. I., 1994: The step-mountain eta coordinate model: Further developments of the convection, viscous sublayer, and turbulence closure schemes. Mon. Wea. Rev., 122, 927-945, https:/doi.org/ 10.1175/1520-0493(1994)122<0927:TSMECM>2.0.CO;2.

Joseph, B., A. Mahalov, B. Nicolaenko, and K. L. Tse, 2004: Variability of turbulence and its outer scales in a model tropopause jet. J. Atmos. Sci., 61, 621-643, https://doi.org/ 10.1175/1520-0469(2004)061<0621:VOTAIO > 2.0.CO;2.

Kim, J.-H., and H.-Y. Chun, 2010: A numerical study of Clear-Air Turbulence (CAT) encounters over South Korea on 2 April 2007. J. Appl. Meteor. Climatol., 49, 2381-2403, https://doi.org/ 10.1175/2010JAMC2449.1.

_ and _ - 2012: A numerical simulation of convectively induced turbulence above deep convection. J. Appl. Meteor. Climatol., 51, 1180-1200, https://doi.org/10.1175/JAMC-D-11-0140.1.
,,-- R. D. Sharman, and S. B. Trier, 2014: The role of vertical shear on aviation turbulence within cirrus bands of a simulated western Pacific cyclone. Mon. Wea. Rev., 142, 27942813, https://doi.org/10.1175/MWR-D-14-00008.1.

Klemp, J., J. Dudhia, and A. Hassiotis, 2008: An upper gravitywave absorbing layer for NWP applications. Mon. Wea. Rev., 136, 3987-4004, https://doi.org/10.1175/2008MWR2596.1.

Köhler, M., M. Ahlgrimm, and A. Beljaars, 2011: Unified treatment of dry convective and stratocumulus-topped boundary layers in the ECMWF model. Quart. J. Roy. Meteor. Soc., 137, 43-57, https://doi.org/10.1002/qj.713.

Kosović, B., D. Muñoz-Esparza, and J. Sauer, 2016: Improving spectral resolution of finite difference schemes for multiscale modeling applications using numerical weather prediction model. 22nd Symp. on Boundary Layers and Turbulence, Salt Lake City, UT, Amer. Meteor. Soc., 3B.5, https://ams.confex.com/ams/ 32AgF22BLT3BG/webprogram/Paper295892.html.

Lane, T. P., and J. C. Knievel, 2005: Some effects of model resolution on simulated gravity waves generated by deep, mesoscale convection. J. Atmos. Sci., 62, 3408-3419, https://doi.org/10.1175/JAS3513.1.

— turbulence revealed by large-eddy simulation. Geophys. Res. Lett., 41, 2221-2227, https://doi.org/10.1002/2014GL059299.

T. L. Clark, and H.-M. Hsu, 2003: An investigation of turbulence generation mechanisms above deep convection. J. Atmos. Sci., 60, 1297-1321, https://doi.org/10.1175/15200469(2003)60<1297:AIOTGM>2.0.CO;2.

Lilly, D. K., 1966: On the application of the eddy viscosity concept in the inertial sub-range of turbulence. National Center for Atmospheric Research, NCAR Manuscript 123, 19 pp.

_ 1967: The representation of small scale turbulence in numerical simulation experiments. IBM Scientific Computing Symp. on Environmental Sciences, Thomas J. Watson Research Center, Yorktown Heights, NY, IBM, 195-210.

Louis, J.-F., 1979: A parametric model of vertical eddy fluxes in the atmosphere. Bound.-Layer Meteor., 17, 187-202, https://doi.org/ 10.1007/BF00117978.

Mahalov, A., B. Nicolaenko, K. Tse, and B. Joseph, 2004: Eddy mixing in jet-stream turbulence under stronger stratification. Geophys. Res. Lett., 31, L23111, https://doi.org/10.1029/2004GL021055.

_, M. Moustaoui, and V. Grubišić, 2011: A numerical study of mountain waves in the upper troposphere and lower stratosphere. Atmos. Chem. Phys. Discuss., 11, 4487-4532, https:// doi.org/10.5194/acpd-11-4487-2011.

Moeng, C.-H., and J. C. Wyngaard, 1988: Spectral analysis of largeeddy simulations of the convective boundary layer. J. Atmos. Sci., 45, 3573-3587, https://doi.org/10.1175/1520-0469(2003) 60<1297:AIOTGM>2.0.CO;2.

Monin, A., and A. Obukhov, 1954: Basic turbulent mixing laws in the atmospheric surface layer. Tr. Inst. Teor. Geofiz. Akad. Nauk. SSSR, 24, 163-187.

Muñoz-Esparza, D., R. Sharman, and J. Lundquist, 2018a: Turbulent dissipation rate in the atmospheric boundary layer: Observations and WRF mesoscale modeling during the XPIA field campaign. Mon. Wea. Rev., 146, 351-371, https://doi.org/10.1175/MWR-D17-0186.1.

$\longrightarrow,-$ J J. Sauer, and B. Kosović, 2018b: Toward low-level turbulence forecasting at eddy-resolving scales. Geophys. Res. Lett., 45, 8655-8664, https://doi.org/10.1029/2018GL078642.

Nakanishi, M., and H. Niino, 2004: An improved Mellor-Yamada level-3 model with condensation physics: Its design and verification. Bound.-Layer Meteor., 112, 1-31, https://doi.org/ 10.1023/B:BOUN.0000020164.04146.98. 
Niu, G.-Y., and Coauthors, 2011: The community Noah land surface model with multiparameterization options (Noah-MP): 1. Model description and evaluation with local-scale measurements. J. Geophys. Res., 116, D12109, https://oi.org/10.1029/ 2010JD015139.

Olson, J. B., J. S. Kenyon, W. Angevine, J. M. Brown, M. Pagowski, and K. Sušelj, 2019a: A description of the MYNN-EDMF scheme and the coupling to other components in WRF-ARW. NOAA Tech. Memo. OAR GSD-61, 42 pp.

— , and Coauthors, 2019b: Improving wind energy forecasting through numerical weather prediction model development. Bull. Amer. Meteor. Soc., 100, 2201-2220, https://doi.org/ 10.1175/BAMS-D-18-0040.1.

Paoli, R., O. Thouron, J. Escobar, J. Picot, and D. Cariolle, 2014: High-resolution large-eddy simulations of stably stratified flows: Application to subkilometer-scale turbulence in the upper troposphere-lower stratosphere. Atmos. Chem. Phys., 14, 5037-5055, https://doi.org/10.5194/acp-14-5037-2014.

Pielke, R. A., 2013: Mesoscale Meteorological Modeling. Academic Press, 693 pp.

Sakradzija, M., A. Seifert, and A. Dipankar, 2016: A stochastic scale-aware parameterization of shallow cumulus convection across the convective gray zone. J. Adv. Model. Earth Syst., 8, 786-812, https://doi.org/10.1002/2016MS000634.

Sandery, P., and P. Sakov, 2017: Ocean forecasting of mesoscale features can deteriorate by increasing model resolution towards the submesoscale. Nat. Commun., 8, 1566, https:// doi.org/10.1038/s41467-017-01595-0.

Sharman, R., 2016: Nature of aviation turbulence. Aviation Turbulence: Processes, Detection, Prediction, R. Sharman and T. Lane, Eds., Springer, 3-30.

—, L. Cornman, G. Meymaris, J. Pearson, and T. Farrar, 2014: Description and derived climatologies of automated in situ eddy-dissipation-rate reports of atmospheric turbulence. J. Appl. Meteor. Climatol., 53, 1416-1432, https://doi.org/10.1175/JAMCD-13-0329.1.

Shin, H. H., and S.-Y. Hong, 2013: Analysis of resolved and parameterized vertical transports in convective boundary layers at gray-zone resolutions. J. Atmos. Sci., 70, 3248-3261, https:// doi.org/10.1175/JAS-D-12-0290.1.

— and - 2015: Representation of the subgrid-scale turbulent transport in convective boundary layers at gray-zone resolutions. Mon. Wea. Rev., 143, 250-271, https://doi.org/10.1175/ MWR-D-14-00116.1.

Skamarock, W. C., and J. B. Klemp, 2008: A time-split nonhydrostatic atmospheric model for weather research and forecasting applications. J. Comput. Phys., 227, 3465-3485, https://doi.org/10.1016/j.jcp.2007.01.037.

—_, and A. Gassmann, 2011: Conservative transport schemes for spherical geodesic grids: High-order flux operators for odebased time integration. Mon. Wea. Rev., 139, 2962-2975, https://doi.org/10.1175/MWR-D-10-05056.1.

— , and Coauthors, 2008: A description of the Advanced Research WRF version 3. NCAR Tech. Note NCAR/TN475+STR, 113 pp., https://doi.org/10.5065/D68S4MVH.

—, C. Snyder, J. B. Klemp, and S.-H. Park, 2019: Vertical resolution requirements in atmospheric simulation. Mon. Wea. Rev., 147, 2641-2656, https://doi.org/10.1175/MWR-D-19-0043.1.

Smagorinsky, J., 1963: General circulation experiments with the primitive equations: I. The basic experiment. Mon. Wea. Rev., 91, 99-164, https://doi.org/10.1175/1520-0493(1963)091<0099: GCEWTP $>2.3$.CO;2.

- 1993: Some historical remarks on the use of nonlinear viscosities. Large Eddy Simulation of Complex Engineering and
Geophysical Flows, B. Galperin and St. A. Orszag, Eds., Cambridge University Press, 3-36

Smith, T. L., S. G. Benjamin, J. M. Brown, S. Weygandt, T. Smirnova, and B. Schwartz, 2008: Convection forecasts from the hourly updated, 3-km High Resolution Rapid Refresh (HRRR) model. 24th Conf. on Severe Local Storms, Savannah, GA, Amer. Meteor. Soc., 11.1, https://ams.confex.com/ams/24SLS/ techprogram/paper_142055.htm.

Stull, R. B., 1988: An Introduction to Boundary Layer Meteorology. Kluwer Academic, 666 pp.

Thompson, G., P. R. Field, R. M. Rasmussen, and W. D. Hall, 2008: Explicit forecasts of winter precipitation using an improved bulk microphysics scheme. Part II: Implementation of a new snow parameterization. Mon. Wea. Rev., 136, 5095-5115, https://doi.org/10.1175/2008MWR2387.1.

Trier, S. B., and R. D. Sharman, 2009: Convection-permitting simulations of the environment supporting widespread turbulence within the upper-level outflow of a mesoscale convective system. Mon. Wea. Rev., 137, 1972-1990, https://doi.org/10.1175/2008MWR2770.1.

— and - 2016: Mechanisms influencing cirrus banding and aviation turbulence near a convectively enhanced upper-level jet stream. Mon. Wea. Rev., 144, 3003-3027, https://doi.org/ 10.1175/MWR-D-16-0094.1.

-,- R. Fovell, and R. Frehlich, 2010: Numerical simulation of radial cloud bands within the upper-level outflow of an observed mesoscale convective system. J. Atmos. Sci., 67, 2990-2999, https://doi.org/10.1175/2010JAS3531.1.

__ _ _ a and T. P. Lane, 2012: Influences of moist convection on a cold-season outbreak of Clear-Air Turbulence (CAT). Mon. Wea. Rev., 140, 2477-2496, https://doi.org/10.1175/ MWR-D-11-00353.1.

, D. Muñoz-Esparza, and T. Lane, 2020: Environment and mechanisms of severe turbulence in a midlatitude cyclone. J. Atmos. Sci., https://doi.org/10.1175/JAS-D-20-0095.1, in press.

Von Neumann, J., and R. D. Richtmyer, 1950: A method for the numerical calculation of hydrodynamic shocks. J. Appl. Phys., 21, 232-237, https://doi.org/10.1063/1.1699639.

Wagner, A., D. Heinzeller, S. Wagner, T. Rummler, and H. Kunstmann, 2018: Explicit convection and scale-aware cumulus parameterizations: High-resolution simulations over areas of different topography in Germany. Mon. Wea. Rev., 146, 1925-1944, https://doi.org/10.1175/MWR-D-17-0238.1.

Walters, D., and Coauthors, 2019: The Met Office Unified Model global atmosphere 7.0/7.1 and JULES global land 7.0 configurations. Geosci. Model Dev., 12, 1909-1963, https://doi.org/ 10.5194/gmd-12-1909-2019.

Wyngaard, J. C., 2004: Toward numerical modeling in the "terra incognita." J. Atmos. Sci., 61, 1816-1826, https://doi.org/ 10.1175/1520-0469(2004)061<1816:TNMITT>2.0.CO;2.

Zhang, X., J.-W. Bao, B. Chen, and E. D. Grell, 2018: A threedimensional scale-adaptive turbulent kinetic energy scheme in the WRF-ARW model. Mon. Wea. Rev., 146, 2023-2045, https://doi.org/10.1175/MWR-D-17-0356.1.

Zhou, B., J. S. Simon, and F. K. Chow, 2014: The convective boundary layer in the terra incognita. J. Atmos. Sci., 71, 25452563, https://doi.org/10.1175/JAS-D-13-0356.1.

Zovko-Rajak, D., and T. P. Lane, 2014: The generation of nearcloud turbulence in idealized simulations. J. Atmos. Sci., 71, 2430-2451, https://doi.org/10.1175/JAS-D-13-0346.1.

,,-- R. D. Sharman, and S. B. Trier, 2019: The role of gravity wave breaking in a case of upper-level near-cloud turbulence. Mon. Wea. Rev., 147, 4567-4588, https://doi.org/ 10.1175/MWR-D-18-0445.1. 